Discussion Paper No. 04-40

\title{
Assessing Emission Allocation in Europe: An Interactive Simulation Approach
}

Christoph Böhringer, Tim Hoffmann, Andreas Lange, Andreas Löschel and Ulf Moslener

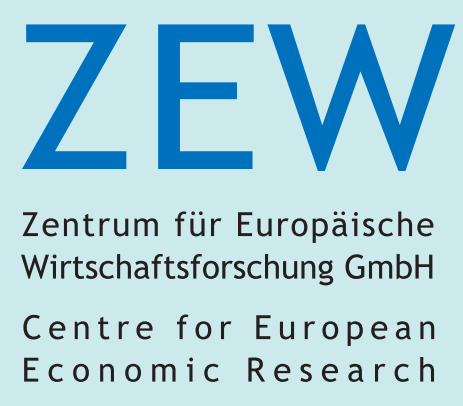


Discussion Paper No. 04-40

\title{
Assessing Emission Allocation in Europe: An Interactive Simulation Approach
}

\author{
Christoph Böhringer, Tim Hoffmann, Andreas Lange, \\ Andreas Löschel and Ulf Moslener
}

Download this ZEW Discussion Paper from our ftp server:

ftp://ftp.zew.de/pub/zew-docs/dp/dp0440.pdf

Die Discussion Papers dienen einer möglichst schnellen Verbreitung von neueren Forschungsarbeiten des ZEW. Die Beiträge liegen in alleiniger Verantwortung der Autoren und stellen nicht notwendigerweise die Meinung des ZEW dar.

Discussion Papers are intended to make results of ZEW research promptly available to other economists in order to encourage discussion and suggestions for revisions. The authors are solely responsible for the contents which do not necessarily represent the opinion of the ZEW. 


\section{Nontechnical Summary}

The EU-wide emissions trading scheme covering major $\mathrm{CO}_{2}$ production sites will be enacted in 2005. Many design issues - most notably the initial allocation of allowances - are left to EU Member States. Under the EU emissions trading Directive Member States must draw up National Allocation Plans (NAPs) in which they (i) allocate the national emissions budget defined in the EU burden sharing agreement (EU BSA) to the different sectors of the economy and (ii) lay down the general rules that govern the initial emissions allocation to the firms eligible for emissions trading.

This paper quantitatively analyzes aspects of efficiency and sectoral burden sharings that may result from different allocation rules.

Furthermore it presents a flexible web-based simulation model where the user can specify the design of National Allocation Plans for each EU-Member State an then evaluate the cost implications at the regional and sectoral level.

Our analysis focuses on the hybrid nature of the EU trading scheme, i.e. a mixture of different regulatory regimes: some sectors (industry and energy) are included in the trading scheme while others (e.g., transport, services) are not. The co-existence of an emissions trading and a non-trading part of the economy poses the problem of partitioning the overall emissions budget between the two parts of the economy. We show that this can dramatically increase the compliance costs of emission regulation.

Our qualitative assessment is based on a simple partial equilibrium model for the EU-15 $\mathrm{CO}_{2}$ market using marginal abatement cost curves that are specified separately for the trading and the non-trading sector. Implementation of the EU BSA is simulated for illustrative policy scenarios: (i) without emissions trading; (ii) with emissions trading and the overall optimal allocation of permits to the trading and non-trading sectors and (iii) with emissions trading where the trading sectors receive enough permits such they can emit at their business-as-usual levels. 


\title{
Assessing Emission Allocation in Europe: An Interactive Simulation Approach
}

Christoph Böhringer ${ }^{\mathrm{a}, \mathrm{b}, \mathrm{c}}$, Tim Hoffmann ${ }^{\mathrm{a}}$, Andreas Lange ${ }^{\mathrm{a}, \mathrm{b}}$, Andreas Löschel ${ }^{\mathrm{a}}$, Ulf Moslener ${ }^{\mathrm{a}}$

\begin{abstract}
Implementation of an EU-wide emissions trading system by means of National Allocation Plans is at the core of European environmental policy agenda. Member States are faced with the problem of allocating their national emission budgets under the EU Burden Sharing Agreement between energy-intensive sectors that are eligible for international emissions trading and the remaining segments of their economies that will be subject to complementary domestic emission regulation. The country-specific segmentation of national emission budgets between trading sectors and non-trading sectors will determine the cost efficiency of the EU emissions trading system and the gains for each Member State vis-à-vis domestic abatement policies. We present an interactive simulation model where users can specify the design of National Allocation Plans for each EU Member State and then evaluate the induced economic effects. Our numerical framework is based on marginal abatement cost curves for (emissions) trading and non-trading sectors of the EU-15 economies. Illustrative simulations highlight the importance of a coordinated design of National Allocation Plans in order to avoid substantial excess costs of regulation and drastic burden shifting between nontrading and trading sectors.
\end{abstract}

JEL classification: D61, H21, H22, Q58

Keywords: emissions trading, allowance allocation, National Allocation Plans

Acknowledgements: We are gratefully acknowledge financial support from the Research DG, European Commission. The views expressed are those of the authors and should not be attributed to the European Commission.

\footnotetext{
${ }^{a}$ Centre for European Economic Research (ZEW), P.O. Box 1034 43, 68034 Mannheim, Germany.

${ }^{\mathrm{b}}$ Institute for Interdisciplinary Environmental Economics, University of Heidelberg, Germany.

${ }^{c}$ Corresponding author: boehringer@zew.de
} 


\section{Introduction}

In 2005, an EU-wide emissions trading scheme (EU (2003)) that covers major $\mathrm{CO}_{2}$ producing sites shall come into force. The key objective of the trading scheme is to promote costefficiency of carbon reduction under the EU Burden Sharing Agreement which prescribes specific commitments for the abatement of greenhouse gas emissions across EU Member States (EU (1999)).

Prior to the enactment of the European trading scheme, each EU Member State must develop a National Allocation Plan that defines the overall cap on carbon emissions for installations included in the trading scheme as well as specifies the allocation rule for allowances. Complementary domestic abatement policies must be undertaken in the sectors not covered by the emissions trading scheme in order to balance the countries' emission budgets as given by the EU Burden Sharing Agreement.

While aiming at cost-efficiency, each Member State has to account for two central constraints in the design of National Allocation Plans:

(i) allocation of emission allowances to installations (sectors) covered by the trading scheme must be mainly for free ${ }^{1}$, and

(ii) competitive distortions involving different treatment of identical installations (firms or sectors) across EU countries should be avoided. ${ }^{2}$

Considering these as guidelines for the implementation of the EU emissions trading scheme, Böhringer and Lange (2004) have shown that it is generally impossible to preserve efficiency while requiring free allocation of emission allowances and non-discrimination of similar firms across countries. The intuition is straightforward: Overall efficiency implies equalized marginal abatement costs across all emitters within the EU.

\footnotetext{
${ }^{1}$ Member States must allocate $95 \%$ of emission allowances dedicated to the emissions trading sectors for free in the "warm-up" phase from 2005 to 2007. In the next phase - from 2008 to 2012 - this threshold can be reduced to $90 \%$, whereas the rules for later phases have been not yet decided upon.

${ }^{2}$ The National Allocation Plans will be scrutinized by the EU Commission with respect to "common criteria" such as competitive distortions (Annex III, EU (2003)).
} 
Even if countries were fully identical, differences in exogenous emission reduction requirements - as prescribed by the EU Burden Sharing Agreement - imply that identical firms will face diverging specific allowance assignments, i.e. allocation factors. ${ }^{3}$ When adopting harmonized rules for free allowance allocation, Böhringer and Lange (2004) point out two policy options in order to achieve identical allocation factors and, thus, avoid competitive distortions between identical firms within the EU emissions trading scheme: Starting from a cost-efficient partitioning of the national emission budget between trading sectors (i.e. sectors covered by the EU emissions trading scheme) and the non-trading sectors (i.e. sectors outside the EU emissions trading scheme) of the economy, a national government may implement harmonized (exogenous) allocation factors by:

(i) either auctioning off or buying the remaining permits corresponding to the difference between the efficient amount of permit allowances for the trading sectors and the country's overall emission budget under the EU Burden Sharing Agreement, or

(ii) re-adjusting the initial partitioning of the country's overall emission budget to meet the prescribed allocation factor.

The two options differ substantially with respect to their implications for overall efficiency and free allowance allocation, i.e. compensation to energy-intensive firms covered by the EU emissions trading scheme. The first option preserves efficient partitioning of national emission budgets but is in conflict with the requirement of free allowance allocation to trading sectors. The second option, in turn, maintains free allocation of emission allowances but involves potentially large efficiency losses as the re-partitioning of the country's emission budget implies differences between marginal abatement costs of the EU-wide trading scheme and the domestic marginal abatement costs in the non-trading segments of each EU Member State.

\footnotetext{
${ }^{3}$ The allocation factor is defined as the ratio between assigned emission allowances and some historic emission base.
} 
This paper complements basic economic reasoning with an interactive simulation model based on marginal abatement cost functions for sectors subject to emissions trading in the EU scheme (thereafter referred to as DIR sectors) and those sectors subject to complementary domestic emission regulation (thereafter referred to as NDIR sectors). The model is able to quantify the inherent trade-offs between efficiency, compensation, and competition neutrality for alternative designs of National Allocation Plans in EU Member States. The interested reader can access the model through a web-interface (http://brw.zew.de/simac/), specify abatement cost functions, set up National Allocation Plans, and calculate the associated economic implications.

An important feature of our interactive simulation model is the assessment of emission regulation costs not only at the level of EU Member States but also for trading energyintensive $D I R$ sectors as well as non-trading NDIR sectors. In the policy debate on appropriate allocation factors for the DIR sectors, it is often overlooked that compensation to $D I R$ sectors via generous allocation factors implies larger reduction requirements and hence higher economic costs for NDIR sectors given that both segments of the economy together are only endowed with the overall national emission budget under the EU Burden Sharing Agreement. Therefore, the design of National Allocation Plans does not only bear an efficiency dimension due to the hybrid regulation of $D I R$ and NDIR sectors but also a potentially important equity dimension. In policy-relevant simulations, we find that National Allocation Plans warranting EU-wide uniform allocation factors of one (i.e. DIR sectors are allocated their business-as-usual emissions) induce total costs that are 10 times higher than the aggregate costs for an efficient trading scheme and 6 times higher than purely domestic abatement action (without international emissions trading). The associated cost for NDIR sectors increase substantially vis-à-vis the efficient regulation while the respective costs for DIR sectors fall to zero.

The remainder of the paper is structured as follows. In section 2, we develop a simple analytical framework to demonstrate the trade-offs between efficiency, compensation and harmonization (competitive neutrality) inherent to the forthcoming implementation of the 
hybrid EU regulation scheme. In section 3, we present a numerical framework based on marginal abatement cost curves to assess the economic implications of alternative National Allocation Plans. In section 4, we discuss the economic implications of illustrative policy scenarios. In section 5, we conclude. Instructions for the use of the interactive web-interface and the concrete algebraic model formulation (including the program code) are relegated to the Appendix.

\section{Analytical Framework}

We set up a simple stylized partial model to illustrate the implicit trade-offs between three central policy objectives underlying the forthcoming implementation of an EU-wide emissions trading scheme: efficiency, compensation, and harmonization.

We consider $R$ regions $(r=1, \ldots, R)$. Each region is constrained by an aggregate emission budget $\bar{E}_{r}$ (as given for EU Member States by the Burden Sharing Agreement). In designing the National Allocation Plan each government has to decide on the number of emission allowances it wants to distribute to the $D I R$ sectors eligible for emissions trading, the fraction with respect to $\bar{E}_{r}$ being denoted by $\theta_{r}$. The remaining part $-\left(1-\theta_{r}\right) \bar{E}_{r}-$ constitutes the emission budget for the NDIR sectors which are not included in the trading system. Aggregate abatement costs in $D I R$ sectors are given by $C_{r}^{D I R}(e)$ with $\left(\partial C_{r}^{D I R} / \partial e \leq 0\right.$, $\left.\partial^{2} C_{r}^{D I R} / \partial e^{2}>0\right)$, and likewise for NDIR sectors by $C_{r}^{N D I R}(e)$ with $\left(\partial C_{r}^{N D I R} / \partial e \leq 0\right.$, $\left.\partial^{2} C_{r}^{N D I R} / \partial e^{2}>0\right)$, where $e$ denotes emissions. Total abatement costs are represented by $C_{r}\left(E_{r}\right)$ with the same curvature properties.

\section{Efficiency}

Aggregate efficiency requires minimization of total abatement costs of all regions ${ }^{4}$ :

\footnotetext{
${ }^{4}$ We assume that the reduction target must be achieved within the EU: There are neither international emissions trading opportunities beyond EU borders nor abatement options using project-based mechanisms like the Clean Development Mechanism that could further reduce overall compliance costs.
} 
$\min _{e_{r}^{D I R}, e_{r}^{N D I R}} \sum_{r}\left[C_{r}^{D I R}\left(e_{r}^{D I R}\right)+C_{r}^{N D I R}\left(e_{r}^{N D I R}\right)\right]$
s.t. $\sum_{r}\left(e_{r}^{D I R}+e_{r}^{N D I R}\right)=\sum_{r} e_{r}^{D I R}+\sum_{r} e_{r}^{N D I R}=\sum_{r} \theta_{r} \bar{E}_{r}+\sum_{r}\left(1-\theta_{r}\right) \bar{E}_{r}=\sum_{r} \bar{E}_{r}$

Denoting the Lagrange multiplier with $\sigma$, and differentiating with respect to $e_{r}^{D I R}$ and $e_{r}^{N D I R}$, we obtain the first-order condition of equalized marginal abatement costs across all emission sources:

$$
\sigma=-\frac{\partial C_{r}}{\partial E_{r}}=-\frac{\partial C_{r}^{D I R}}{\partial e_{r}^{D I R}}=-\frac{\partial C_{r}^{N D I R}}{\partial e_{r}^{N D I R}}
$$

The resulting optimal emission levels are denoted by $E_{r}^{*}, e_{r}^{D I R^{*}}, e_{r}^{N D I R^{*}}$ where $E_{r}^{*}=e_{r}^{D I R^{*}}+e_{r}^{N D I R^{*}}$. The difference between the exogenous emission budget $\bar{E}_{r}$ and aggregate optimal emissions $E_{r}^{*}$, i.e. $\bar{E}_{r}-E_{r}^{*}$, renders the optimal trade volume in emission allowances. Figure 1 illustrates the case where domestic abatement costs to reach the domestic target $\bar{E}_{r}$ are below the international emission price; hence, the region becomes an exporter of emission allowances.

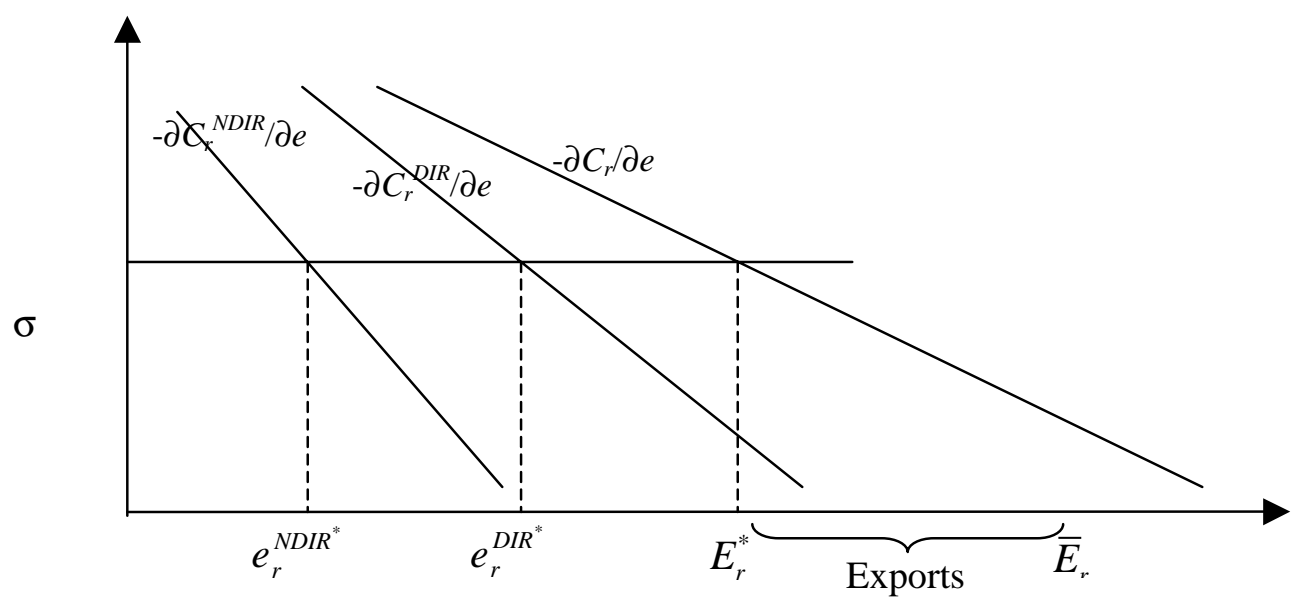

Figure 1: Optimal emissions in NDIR and DIR sectors at international emissions price $\sigma$

From the perspective of an (EU-) social planner, the efficient solution could be decentralized by imposing uniform emission taxes at the optimal rate $\sigma$ on the NDIR sectors. The remaining emission budget, $\bar{E}_{r}-e_{r}^{N D I R^{*}}$, would then be given as initial endowment to the DIR sectors 
eligible for international emissions trading, i.e. the optimal fraction of the regional emission budget to be allocated to DIR sectors amounts to $\theta_{r}^{*}=\left(\bar{E}_{r}-e_{r}^{N D I R^{*}}\right) / \bar{E}_{r}$.

\section{Compensation}

Compensation to DIR sectors has been a conditio-sine-qua-non for the legal approval of the trading initiative by the EU Parliament. In this vein, implementation of the EU trading scheme via National Allocation Plans prescribes free allocation of emission allowances to $D I R$ sectors. As to allocation rules, two approaches are prominently discussed: Emission allocation should be based on output levels (benchmarking) or on historic emissions (grandfathering). Applied to historic data, these rules boil down to lump-sum transfers to firms in the DIR sectors. ${ }^{5}$ Reflecting current policy proposals, we assume that firms in the $D I R$ sectors receive an initial allocation of allowances based on some historic emission level $e_{r, D I R}^{0}$. The total allocation of allowances to DIR sectors in region $r$, i.e. $\theta_{r} \bar{E}_{r}$, is determined by the allocation factor $\lambda_{r}$ according to:

$$
\theta_{r}^{*} \bar{E}_{r}=\lambda_{r} \bar{e}_{r, D I R}^{0}
$$

\section{Harmonization}

From a legal point of view, requests for harmonized National Allocation Plans imply equal compensation of identical firms across different countries. In practical terms, this means that allocation factors $\lambda_{r}$ should be the same across identical firms.

\section{Trade-offs between efficiency, compensation and harmonization}

Under efficient partitioning of national emission budgets and (non-distortionary) static emission-based allocation of free allowances the endogenous allocation factors $\lambda_{r}=\frac{\theta_{r}^{*} \bar{E}_{r}}{\bar{e}_{r, D I R}}$

\footnotetext{
${ }^{5}$ In contrast, distortions and efficiency losses result if the basis for allocation is updated over time. Such dynamic allocation rules provide strategic incentives to increase output and/or emission intensity and thus work as distortionary subsidies. Böhringer and Lange (2003) provide a generic analysis of the economic implications of dynamic allocation schemes for emission allowances. They find that in open trading systems - where the allowance price is perceived as exogenous - emission-based allocation is more distortionary than output-based allocation since it does not only distort production but also emission intensities.
} 
will generally differ across regions. If harmonization is the primary policy objective, this means either giving up on efficiency (by re-adjusting $\theta_{r}$ ) or on comprehensive compensation (by auctioning potentially larger parts of the efficient emission budget for $D I R$ sectors $\left.e_{r}^{D I R^{*}}=\theta_{r}^{*} \bar{E}_{r}\right)$.

\section{Numerical Framework}

In order to quantify the policy relevance of the trade-offs between efficiency, compensation, and harmonization, we transform the stylized analytical framework of section 2 into a simple numerical model based on marginal abatement cost curves for DIR and NDIR sectors in the EU-15. They are calibrated to empirical data.

\section{Model Parameterization}

Marginal costs of emission abatement may vary considerably across countries and sectors due to differences in carbon intensity, initial energy price levels, or the ease of carbon substitution possibilities. Continuous marginal abatement cost curves for the DIR and NDIR sectors in EU countries can be derived from a sufficiently large number of discrete observations for marginal abatement costs and the associated emission reductions in the DIR and NDIR sectors. In applied research these values are often generated by partial equilibrium models of the energy system (such as the POLES model by Criqui and Mima (2001) or the PRIMES model by Capros et al. (1998)), that embody a detailed bottom-up description of technological options. Another possibility is to derive marginal abatement cost curves from computable general equilibrium (CGE) models (see e.g. Reilly et al. (1999) or Eyckmans et al. (2001)). We adopt the latter approach and generate a reduced form of complex CGE interactions in terms of marginal abatement cost curves that are directly accessible to the nonCGE specialist. In order to obtain such marginal abatement cost curves for the DIR and NDIR sectors across EU countries, we make use of a standard static multi-region, multi-sector CGE model for the EU economy (see Böhringer (2002) for a detailed algebraic exposition) based on the most recent consistent accounts of EU Member States' production and consumption, 
bilateral trade and energy flows for 1997 (as provided by the GTAP5-E database - see Dimaranan and McDougall (2002)). With respect to the analysis of carbon abatement policies, the sectors in the model have been carefully selected to keep the most carbonintensive sectors in the available data as separate as possible. The energy goods identified in the model include primary carriers (coal, natural gas, crude oil) and secondary energy carriers (refined oil products and electricity). Furthermore, the model features three additional energyintensive non-energy sectors (iron and steel; paper, pulp and printing; non-ferrous metals) whose installations - in addition to the secondary energy branches (refined oil products and electricity) - are subject to the EU emissions trading system. The remaining manufacturers and services are aggregated to a composite industry that produces a non-energy-intensive macro good, which together with final demand captures the activities (NDIR segments) that are not included in the EU trading system.

To generate our reduced form model, we perform a sequence of carbon tax scenarios for each region where we impose uniform carbon taxes (starting from $0 €$ to $200 €$ per ton of carbon in iso-distant steps of $1 €$ ). We thereby generate a large number of marginal abatement costs, i.e. carbon taxes, and the associated emission reductions in DIR and NDIR sectors. The final step involves a fit to the set of "observations". Various types of functional forms could be employed. Common forms include iso-elastic exponential functions (of the type $\left.-C^{\prime}(e)=a \cdot\left(e_{o}-e\right)^{b}\right), \quad$ quadratic or more elaborate polynomial functions $\left(-C^{\prime}(e)=a_{1} \cdot\left(e_{o}-e\right)+a_{2} \cdot\left(e_{o}-e\right)^{2}+\ldots\right) \quad$ as $\quad$ well as exponential functions $\left(-C^{\prime}(e)=a \cdot \exp \left(b \cdot\left(e_{o}-e\right) / e_{0}\right)\right)$ (see e.g. Reilly et al. (1999) or Böhringer and Löschel (2003)). ${ }^{6}$ For our numerical framework, we apply a least-square fit by a polynomial of third degree which provides sufficient flexibility.

\footnotetext{
${ }^{6}$ Baseline emission levels $e_{o}$ do not impose a binding emission reduction - hence, the associated marginal abatement costs for emission use at the baseline level are zero. Clearly, zero marginal abatement costs also hold for emission levels $e>e_{o}$.
} 
The functional form of the marginal abatement cost curves in region $\mathrm{r}$ for the DIR and NDIR sectors is, thus, given by:

$-C_{i r}^{\prime}\left(e_{i r}\right)=a_{1, i r}\left(e_{o_{i r}}-e_{i r}\right)+a_{2, i r}\left(e_{o_{i r}}-e_{i r}\right)^{2}+a_{3, i r}\left(e_{o_{i r}}-e_{i r}\right)^{3} \quad i \in\{D I R, N D I R\}$

Table 1 lists the associated least-square estimates for the coefficients of marginal abatement cost curves across regions. Costs are measured in 1997 dollars per ton of carbon, while the quantities are measured in million tons of carbon.

Table 1: Coefficients for marginal abatement cost functions (base-year: 1997)

\begin{tabular}{lrrr|rrr}
\hline & \multicolumn{3}{c|}{ Directive Sectors $(D I R)$} & \multicolumn{3}{c}{ Non-Directive Sectors (NDIR) } \\
\hline Austria & $a_{1, \text { IIR, }}$ & $a_{2, \text { IIR,r }}$ & $a_{3, \text { DIR,r }}$ & $a_{1, N D I R, r}$ & $a_{2, N D I R, r}$ & $a_{3, N D I R, r}$ \\
Belgium & 33.90 & 6.24 & 9.39 & 153.68 & 11.28 & 34.90 \\
Denmark & 13.60 & -0.49 & 0.99 & 32.68 & 2.28 & 0.35 \\
Finland & 8.57 & -1.82 & 0.46 & 94.97 & 29.05 & -0.78 \\
France & 26.44 & 3.41 & 1.01 & 104.07 & 30.23 & 16.55 \\
Germany & 11.27 & 0.59 & 0.25 & 8.86 & 0.24 & 0.00 \\
Greece & 1.60 & 0.00 & 0.00 & 5.77 & 0.08 & 0.00 \\
Ireland & 19.52 & -1.08 & 0.45 & 61.59 & 2.87 & 2.36 \\
Italy & 8.55 & 19.52 & 15.70 & 169.53 & 61.00 & 41.43 \\
Netherlands & 4.41 & 0.10 & 0.01 & 12.78 & -0.40 & 0.11 \\
Portugal & 3.61 & 1.22 & 0.08 & 18.22 & 0.52 & 0.07 \\
Spain & 29.20 & -1.44 & 9.85 & 83.66 & 28.48 & -1.27 \\
Sweden & 6.29 & -0.01 & 0.07 & 18.32 & 0.78 & 0.01 \\
U.K. & 49.51 & 0.32 & 38.26 & 104.01 & 14.25 & -0.06 \\
\hline
\end{tabular}

Obviously, simulation results are sensitive to both the quality of the fit as well as the accuracy of the underlying "observations". In our case, marginal abatement cost functions capture the economic costs of reducing carbon at a historical point in time, i.e. 1997. If regulation applies to future periods, the prospective adjustment costs must be measured against the projected business-as-usual. The concrete assessment of future marginal and inframarginal abatement costs then hinges on baseline projections for the economy which - given the uncertainty about the future - is a challenge for quantitative analysis and demands for comprehensive 
sensitivity analysis. In our context, Table 2 illustrates the impact of the base-year choice on the magnitude of effective emission reduction requirements which are a key driver of marginal and inframarginal costs.

Table 2: Carbon emissions and reduction requirements (EUROSTAT (2002) and EiE (1999))

\begin{tabular}{lrrr|rrr}
\hline & \multicolumn{2}{c}{$\mathrm{CO}_{2}$ - Emissions } & \multicolumn{3}{c}{$\begin{array}{c}\text { Reduction requirements } \\
\text { (in \% with respect to) }\end{array}$} \\
\hline Austria & 1990 & 1997 & $2010^{*}$ & 1990 & 1997 & $2010^{*}$ \\
Belgium & 55 & 59.4 & 64.2 & 13 & 19.4 & 25.5 \\
Denmark & 117.7 & 132 & 115.1 & 7.5 & 17.5 & 5.4 \\
Finland & 55.7 & 68.6 & 59 & 21 & 35.9 & 25.4 \\
France & 53.5 & 60.1 & 64.9 & 0 & 11 & 17.6 \\
Germany & 362.3 & 367.8 & 462 & 0 & 1.5 & 21.6 \\
Greece & 950.8 & 837.5 & 837.8 & 21 & 10.3 & 10.3 \\
Ireland & 79.2 & 92.8 & 133.8 & -25 & -6.7 & 26 \\
Italy & 29.7 & 36.7 & 46.9 & -13 & 8.6 & 28.4 \\
Netherlands & 399.3 & 409.9 & 451 & 6.5 & 8.9 & 17.2 \\
Portugal & 187.4 & 207.5 & 185.9 & 6 & 15.1 & 5.2 \\
Spain & 41.1 & 49.5 & 60.9 & -27 & -5.4 & 14.3 \\
Sweden & 216 & 260.7 & 288.9 & -15 & 4.7 & 14 \\
U.K. & 52.8 & 55.7 & 53.2 & -4 & 1.4 & -3.2 \\
\hline EU (total) & 575.7 & 538.6 & 584.8 & 12.5 & 6.5 & 13.9 \\
\hline & 3176.2 & 3176.8 & 3408.4 & 8.4 & 8.4 & 14.6 \\
\hline
\end{tabular}

*Emissions as projected in EiE (1999)

The first three columns list the carbon emissions for 1990 (the reference year of the reduction commitments under Kyoto and the EU Burden Sharing Agreement), for 1997 (the base-year for our model simulations) as well as the projected emissions for 2010 (the central year for which emission reduction should be achieved). ${ }^{7}$ The effective reduction targets under the Burden Sharing Agreement can change dramatically along the time-path. While Germany, for example, starts out with a rather stringent reduction target of $21 \%$ with respect to 1990 , the effective reduction target halves with respect to baseline emission levels in 1997 or 2010.

\footnotetext{
${ }^{7}$ The commitment period for achieving on average the emission reduction targets under Kyoto and the EU Burden Sharing Agreement is 2008-2012.
} 
Spain, in turn, had been attributed an emission budget of $15 \%$ in excess of its 1990 emissions but due to economic growth faces an effective reduction of $6 \%$ in 1997 which rises up to 14 \% vis-à-vis projected business-as-usual emission levels in 2010.

For reasons of uncertainties and potentially large inconsistencies associated with business-asusual projections, we base our simulation analysis on historical data for 1997 - the most recent year for which a consistent economic data set at the EU level is available. Acknowledging the importance of the reference period, however, our web-based interface accommodates the flexible parameterization of marginal abatement cost functions and associated base-year-emissions.

\section{Partial versus General Equilibrium Analysis}

The reduced form representation of economy-wide adjustment to emission regulation provides a transparent and easy access to numerical analysis. A potential drawback of such a simplifying approach is the neglect of market interaction and spillover effects. There are several articles illustrating the importance of such indirect effects (Böhringer (2002), Böhringer and Rutherford (2002), Bernard et al. (2003), Klepper and Peterson (2002)). In the context of carbon abatement policies, induced terms-of-trade effects on fossil fuel markets may substantially alter the direct costs of abatement. Depending on the magnitude of global cuts in fossil fuel demand and the level of fossil fuel supply elasticities, a drop in international fuel prices provides secondary benefits for fossil fuel importers while it hurts fossil fuel exporters. Adjustment costs in one country thus generally depend on how much other countries reduce their emissions.

Against this background, the crucial question regarding the robustness of partial equilibrium results based on marginal abatement cost curves is whether terms-of-trade effects are sufficiently small. For our policy issue, the omission of terms-of-trade effects is in place: On the one hand, when determining the impact of different National Allocation Plans, policies outside the EU can be taken as exogenous. On the other hand, changes in the allocation rules in EU countries do not affect the overall European reduction target, which after all has a 
negligible impact on world prices as EU emission cutback under the Burden Sharing Agreement amounts only to a very small share in global carbon emissions. ${ }^{8}$

Apart from terms-of-trade effects, other potentially important general equilibrium interactions concern revenue-recycling. It is well-known that the manner in which revenues from environmental regulation are recycled to the economy can have a larger impact on the gross costs of environmental policy (see Goulder (1995) or Bovenberg (1999)). Within the National Allocation Plans, a larger part of allowances, i.e. scarcity rents, is handed lump-sum to energy-intensive industries. Thus, omission of alternative recycling strategies can be justified. $^{9}$

\section{$4 \quad$ Policy Scenarios and Results}

\section{Policy Scenarios}

The primary objective of emissions trading is to achieve potential efficiency gains. So-called "where-flexibility" assures that emissions will be abated where it is cheapest across all emitting sources. Full "where-flexibility" implies flexibility across countries - say regional flexibility - and flexibility across the sectors of the economy - say sectoral flexibility. It is the nature of a hybrid emissions trading regime such as the EU scheme for carbon dioxide that sectoral flexibility is restricted in the sense that not all sectors are eligible for trading.

We illustrate the policy relevance of trade-offs between efficiency, compensation and harmonization in implementing National Allocation Plans along three stylized policy scenarios:

(i) NoTrade: The NoTrade scenario delivers a benchmark for the magnitude and distribution of efficiency gains emerging from cross-country flexibility of emission abatement within the EU. Under NoTrade, EU Member States meet the emission reduction

\footnotetext{
${ }^{8}$ The cutback in emissions under the Burden Sharing Agreement amounts to $1.7 \%$ of global carbon use in 1997 and $1 \%$ of projected global carbon use in 2010 with negligible impacts on international fossil fuel prices.

${ }^{9}$ A crude shortcut to an explicit representation of tax interaction effects is the use of estimates for marginal costs of public funds that may be applied ex-post to assess the ,double dividend“ of recycling revenues for cuts in distortionary taxes (see e.g. Böhringer and Rutherford (2002)).
} 
target as prescribed by the Burden Sharing Agreement through domestic action only: Domestic carbon taxes are set sufficiently high to keep with the exogenous emission budget. Here the countries minimize their individual abatement costs but do not trade. This is equivalent to a setting where domestic governments auction off their national emission budget to domestic emitters, i.e. a situation with full sectoral flexibility but without any regional flexibility.

(ii) NAP_Opt: The counterpart to the NoTrade case is the scenario NAP_Opt where National Allocation Plans are coordinated to exploit the full potential of efficiency gains from "where-flexibility" in emission abatement across EU Member States. This implies that the partitioning of national emission budgets between $D I R$ and NDIR sectors assures equalization of marginal abatement costs across all carbon emitters. In technical terms, the cost-efficient design of National Allocation Plans can be derived from unrestricted emissions trading across all sectors and EU Member States. Emissions of NDIR sectors for the cost-efficient solution then determine the remaining budget of emission allowances for the DIR sectors (equal to the difference between the national emission budgets and the NDIR emissions). Obviously, the cost-efficient country-specific allocation factors $\lambda_{r}$ are endogenous. In the NAP_Opt scenario there is full "where-flexibility" including regional and sectoral flexibility.

(iii) NAP_Unity: This scenario accounts for two central elements in the policy debate on the implementation of the EU emissions trading scheme. Firstly, there is the concern regarding competitive distortions due to non-uniform allocation factors across EU countries. Secondly, there are fears that energy-intensive industries in most EU countries will be forced to decrease their production levels as a consequence of binding emission constraints. In our static framework, preserving competition neutrality through uniform allocation factors and warranting business-as-usual production comes down to an allocation factor of unity. The settings for the NAP_Unity scenario reflect these policy considerations by adopting a harmonized allocation factor of $\lambda=1$ (under emissions-based allowance assignment) for all regions. In order to achieve the harmonized allocation factor of unity, the optimal partitioning 
of the national emission budget (as determined by scenario NAP_Opt) will be abandoned and marginal abatement costs between $D I R$ and $N D I R$ sectors will fall apart inducing an efficiency trade-off due to harmonization. In the NAP_Opt scenario sectoral flexibility between $D I R$ and NDIR sectors is restricted but there is full regional flexibility within the $D I R$ sectors of the regions.

Free emission allocation to DIR sectors is based on historic emissions of these sectors for the base-year 1997. Table 3 provides a summary of the central policy settings across the four scenarios.

Table 3: Overview of scenario characteristics

\begin{tabular}{|c|c|c|c|c|}
\hline \multirow{2}{*}{ Scenario } & \multicolumn{2}{|c|}{ Regulation Scheme } & \multirow{2}{*}{$\begin{array}{c}\text { International } \\
\text { Emissions Trading }\end{array}$} & \multirow{2}{*}{$\begin{array}{l}\text { Allocation } \\
\text { Factor }\end{array}$} \\
\hline & DIR sectors & NDIR sectors & & \\
\hline NoTrade & $\mathrm{CO}_{2} \operatorname{tax}$ & $\mathrm{CO}_{2} \operatorname{tax}$ & No & None \\
\hline$N A P \_O p t$ & $\begin{array}{l}\text { Permits / } \\
\text { emission-based } \\
\text { allocation }\end{array}$ & $\mathrm{CO}_{2} \operatorname{tax}$ & $\begin{array}{c}\text { Yes } \\
\text { (in DIR sectors) }\end{array}$ & Endogenous \\
\hline NAP_Unity & $\begin{array}{l}\text { Permits / } \\
\text { emission-based } \\
\text { allocation }\end{array}$ & $\mathrm{CO}_{2} \operatorname{tax}$ & $\begin{array}{c}\text { Yes } \\
\text { (in DIR sectors) }\end{array}$ & $\begin{array}{c}\text { Exogenous } \\
\lambda_{r}=1\end{array}$ \\
\hline
\end{tabular}

\section{Results}

Table 4 reports quantitative results for our scenarios on marginal abatement costs as well as total abatement costs differentiated in both DIR and NDIR sectors. Under NoTrade, the marginal abatement costs are equivalent to the domestic carbon tax which EU Member States must levy to achieve their respective emission reduction target under the Burden Sharing Agreement. A key determinant for the magnitude of marginal abatement costs is the effective cutback requirement. Ceteris paribus, the more emissions a country has to reduce, the more costly it is at the margin to substitute away from carbon in production and consumption. 


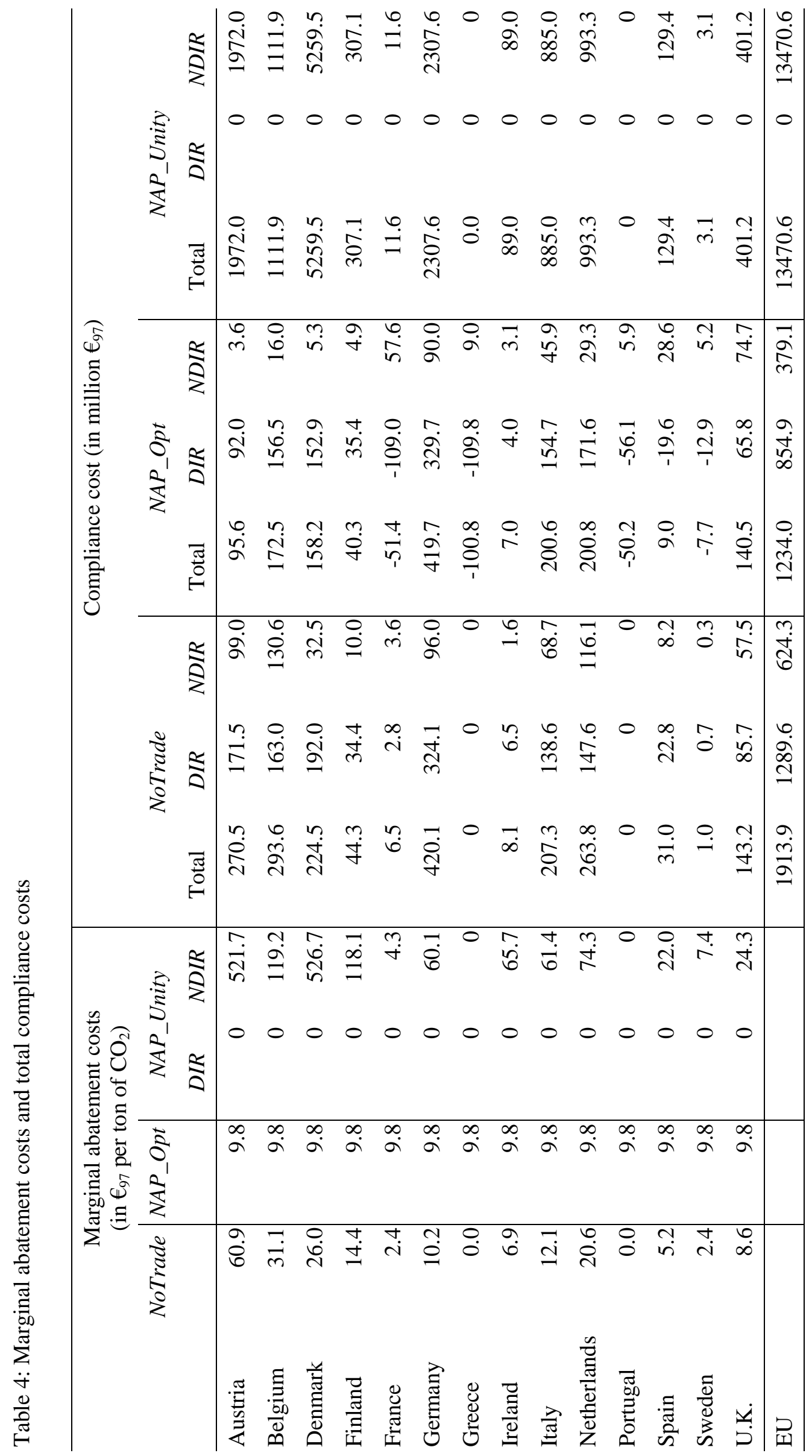


The high marginal abatement costs for regions such as Austria, Belgium, and Denmark reflect large reduction requirements vis-à-vis countries such as Sweden or France that have low marginal costs along with small abatement targets. Clearly, countries that do not face any binding emission target - in our case: Greece and Portugal - have marginal abatement costs of zero. Apart from the magnitude of emission reduction requirements, other important determinants of marginal abatement costs include initial energy prices, carbon intensities, or the ease of carbon substitution in production and consumption activities that are reflected in the slope and curvature of sectoral marginal abatement cost curves. These additional determinants explain why a country (e.g. Austria) may need higher carbon taxes than another country (e.g. Denmark) although its effective percentage reduction target is smaller.

The pronounced differences in marginal abatement costs across EU countries for the NoTrade case result from the lack of regional flexibility. They indicate the potential for efficiency gains from cross-country emissions trading. An efficient implementation of the hybrid regulation under National Allocation Plans would imply equalized marginal abatement costs of $9.9 €$ per ton of $\mathrm{CO}_{2}$ which represents the price of traded emission allowances in the DIR sectors as well as the tax rate to be levied on $\mathrm{CO}_{2}$ emissions in NDIR sectors. The pattern of permit trade emerges from the magnitude of marginal abatement costs under NoTrade vis-àvis the equalized marginal abatement costs for the case of tradable permits. Countries whose marginal abatement costs under NoTrade are below the uniform permit price will sell permits and abate more emissions. In turn, countries whose marginal abatement costs are above the uniform permit price will buy permits and abate less.

Imposition of uniform allocation factors that grant DIR sectors their BAU emission levels, i.e. $\lambda_{r}=1$, imply an effective reduction requirement of zero for these segments given that the base-year for emission allocation coincides with the target year for abatement compliance. ${ }^{10}$

\footnotetext{
${ }^{10}$ Clearly, this is a rather extreme setting but it serves the purpose to illustrate the implications of generous allowance allocation to DIR sectors that appears as a common feature in the concrete specification design of National Allocation Plans across EU Member States.
} 
All the abatement is shifted to NDIR sectors which are excluded from international emissions trading. The hybrid regulation then leads to extremely high marginal abatement costs in the NDIR sectors of several EU Member States.

The differences in marginal abatement costs across scenarios are reflected in the differences of aggregate EU abatement costs under the Burden Sharing Agreement. Total compliance costs amount to nearly 2 billion $€$ for the NoTrade case. These costs can be substantially reduced via implementation of an efficient EU emissions trading scheme. In our case, the cost savings equal more than a third of the NoTrade compliance costs. All countries are better off under efficient trading as compared to purely domestic action. In our partial equilibrium framework - where we neglect terms-of-trade and income effects - this result does not come as a surprise: Comprehensive "where-flexibility" must be pareto-superior.

Ceteris paribus a country's gains from unconstrained "where-flexibility" rise with an increased deviation of its autarky marginal abatement costs from the efficient international permit price. For example, the efficiency gains under NAP_Opt for Germany compared to the NoTrade case are very small (ca. $0.2 \%$ ) since Germany's autarky carbon value is very close to the international permit price. In contrast, Austria gains more than $60 \%$ from efficient trading as its NoTrade marginal abatement costs are six times the international permit price.

Countries which do not face a binding emission constraint under NoTrade unambiguously will have negative costs under NAP_Opt, i.e. they will be better off with EU regulation than without because their revenues from permit sales exceed the domestic abatement costs (here: Greece and Portugal). Likewise countries with relatively low abatement targets may more than offset overall abatement costs with revenues from permit sales (here: France and Sweden)

As soon as we restrict "where-flexibility" at the sectoral level and do not depict the efficient partitioning of national budgets, efficiency implications of carbon trade may be quite different. It is no longer clear that the EU as a whole nor individual Member States will 
benefit vis-à-vis domestic abatement policies (e.g. carbon taxes where part of tax revenues may be recycled lump-sum to energy-intensive industries for compensation purposes).

Scenario NAP_Unity provides evidence on the potential magnitude of efficiency losses through hybrid regulation: Under $N A P_{-}$Unity aggregate costs are 10 times higher than under an efficient trading scheme and 6 times higher than for purely domestic abatement action. In this case, there are no efficiency gains that could be exploited in DIR sectors through regional flexibility because the implied carbon price is zero. All abatement is shifted to the NDIR sectors and must be achieved by domestic policies. Countries, thus, can not take advantage of sectoral flexibility ending up with higher marginal abatement costs for the DIR sectors compared to the NoTrade scenario and zero marginal costs for the NDIR sectors. ${ }^{11}$ As a consequence there occur substantial excess costs even compared to the NoTrade scenario where one assures at least equalization of marginal abatement costs across sectors within the domestic economy.

This leads us to another central insight from our stylized policy analysis. Hybrid regulation may not only deteriorate efficiency in a drastic way but also induce politically delicate burden shifting between $D I R$ and NDIR sectors. Generous compensations to DIR sectors are directly at the expense of NDIR sectors with potentially large increases in marginal and inframarginal costs (see e.g. Austria, Belgium, Denmark, or Finland). The NDIR sectors which do not receive any compensation from scarcity rents in the first place then bear the additional burden of diluting the polluter-pays-principle for DIR sectors. ${ }^{12}$

\footnotetext{
${ }^{11}$ Countries which do not have a binding emission constraint under NoTrade (here: Greece and Portugal) are obviously indifferent between NoTrade and NAP_Unity because marginal abatement costs for $D I R$ and NDIR sectors are zero in both scenarios.

${ }^{12}$ In fact, preferential treatment - including full exemptions - of energy-intensive industries is a common feature in environmental policy practise of all OECD countries (see OECD (2001), p. 78) but in general this is at the expense of environmental effectiveness rather than more stringent regulation for other sectors. In the case of the hybrid EU trading scheme, however, the situation is different as the environmental target is fixed.
} 
Table 5 shows the large differences in endogenous allocation factors for the efficient NAP_Opt scenario.

They range from 0.34 for Denmark up to 1.18 for Greece and provide clear evidence that concerns about competitive distortions between identical firms within the EU can be justified (when keeping with the objectives of overall efficiency and free allowance allocation). The cross-country differences in allocation factors reflect country-and sector-specific differences in the relative ease of carbon mitigation as captured by the curvature of calibrated marginal abatement cost curves.

Finally, we turn to the induced percentage emission reductions at the regional and sectoral level that are reported in Table 5. By definition, the aggregate region's emission reduction must comply with the EU Burden Sharing Agreement for the NoTrade scenario. Within regions, the DIR sectors will contribute relatively more to the reduction requirement which means that carbon abatement options in energy-intensive industries through fuel shifting or energy savings is relatively cheaper than in the NDIR sectors. ${ }^{13}$ For efficient carbon trading the direction and magnitude of changes in autarky emission reductions are driven by the differences between the autarky carbon value and the international permit price (the qualitative movements for $D I R$ and NDIR sectors within a single region are the same). Under NAP_Unity, total emission reduction at the regional level will be the same as under NoTrade because regional flexibility across DIR sectors hasn't any effect. The implied shifts at the sectoral level are, however, dramatic: Under NAP_Unity the NDIR sectors have to deliver the overall regional abatement duties implying very high NDIR percentage reduction for several EU countries.

\footnotetext{
${ }^{13}$ The one exception is France whose electricity sector is mainly based on carbon-free nuclear power whereas in other countries (e.g. Denmark or Germany) power and heat production is carbon-intensive and accounts for a large share of overall DIR carbon emissions. 


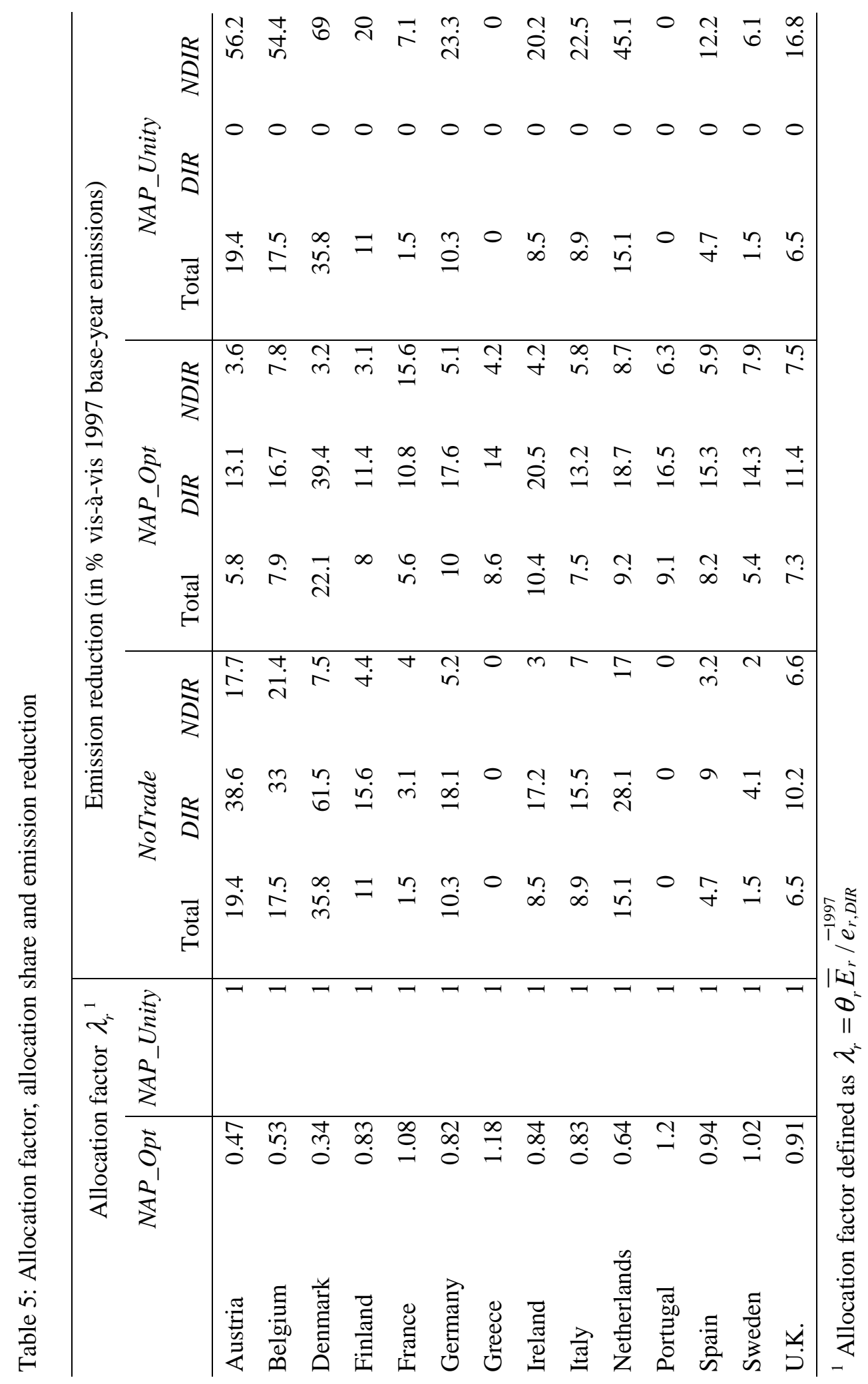




\section{Conclusions}

The forthcoming EU-wide carbon market constitutes a milestone in international environmental policy. It provides the first multi-jurisdictional emissions trading regime and will establish the world-largest market for tradable permits. The concrete implementation via National Allocation Plans entails a hybrid regulation where energy-intensive sectors are eligible for emissions trading and other segments of the economy must be constrained by complementary domestic policy instruments. The hybrid setting creates trade-offs between overall economic efficiency and other objectives of the EU trading scheme, i.e. free allowance allocation of tradable emission permits and equal treatment of comparable energy-intensive sites across EU Member States. In this paper, we have developed a simple quantitative framework that allows the non-technical reader to investigate these trade-offs in a flexible and user-friendly way. Illustrative simulations highlighted the need to re-consider the current guidelines for National Allocation Plans in order to avoid substantial excess costs of regulation and drastic sectoral burden shifting. The hybrid regulation together with compensation (free allowance allocation) of energy-intensive industries may have been necessary in an initial stage to promote market-based regulation of carbon emissions. In the medium-run, comprehensive coverage of all carbon emitters should materialise the full potential of efficiency gains. ${ }^{14}$ Furthermore, the inherent conflict between compensation and harmonisation could be resolved by a gradual transition to an auctioned permit system. The latter simply implies the rigorous adoption of the "polluter pays principle" which - in terms of efficient resource use - should be the guiding principle of any market-based environmental policy.

Finally, it should be stressed that our analysis is of interest beyond the scope of the current debate on National Allocation Plans. The derived insights may not be only useful for the redesign of Allocation Plans across EU Member States in future periods, but also with respect to the specification of any hybrid regulation regime where emissions trading for some sectors is combined with complementary regulation in other sectors.

\footnotetext{
${ }^{14}$ Carbon emissions could be easily controlled upstream via a rather limited number of fuel retailers.
} 


\section{References}

Bernard, A.,S. Paltsev, J.M. Reilly, M. Vielle, and L. Viguier (2003), Russia's Role in the Kyoto Protocol, MIT Joint Program on the Science and Policy of Global Change, Report No. 98, Cambridge, MA.

Böhringer, C. (2002), Industry-level Emission Trading between Power Producers in the EU, Applied Economics, 34 (4), 523-533.

Böhringer, C. and T.F. Rutherford (2002) Carbon Abatement and International Spillovers, Environmental and Resource Economics 22(3), 391-417.

Böhringer, C. and A. Lange (2003), Economic Implications of Alternative Allocation Schemes for Emission Allowances, Discussion Paper 03-22, ZEW (Centre for European Economic Research), Mannheim.

Böhringer, C. and A. Löschel (2003), Market power and hot air in international emissions trading: the impact of US withdrawal from the Kyoto Protocol, Applied Economics, 35, 651-663.

Böhringer, C. and A. Lange (2004), Mission Impossible !? On the Harmonization of National Allocation Plans under the EU Emissions Trading Directive, Discussion Paper 04-15, ZEW (Centre for European Economic Research), Mannheim.

Bovenberg, A. L. (1999), Green Tax Reforms and the Double Dividend: An Updated Reader's Guide, International Tax and Public Finance, 6, 421-443.

Brooke, A., D. Kendrick and A. Meeraus (1987), GAMS: A User's Guide, Scientific Press, South San Francisco.

Capros, P., L. Mantzos, D. Kolokotsas, N. Ioannou, T. Georgakopoulos, A. Filippopoulitis, Y. Antoniou (1998), The PRIMES energy system model - reference manual, National Technical University of Athens, document as peer reviewed by the European Commission, Directorate General for Research.

Criqui, P. and S. Mima (2001), The European greenhouse gas tradable emission permit system: some policy issues identified with the POLES-ASPEN model, ENER Bulletin, 23, p. 5155.

Dimaranan, B. and R.A. McDougall (2002), Global Trade, Assistance and Production: The GTAP 5 Data Base, West Lafayette: Center for Global Trade Analysis, Purdue University. 
Dirkse, S. and M. Ferris (1995), The PATH Solver: A Non-monotone Stabilization Scheme for Mixed Complementarity Problems, Optimization Methods and Software, 5, 123-156.

EiE (1999), European Union Energy Outlook to 2020, Energy in Europe, European Commission, Brussels.

EU (1999), EU Council of Ministers, Commission Communication, Preparing for Implementation of the Kyoto Protocol, COM (1999), Annex 1, available at: http://europa.eu.int/comm/environment/docum/99230 en.pdf.

EU (2003), Directive establishing a scheme for greenhouse gas emission allowance trading within the Community and amending Council directive 96/61/EC, European Commission, Brussels, available at:

http://europa.eu.int/comm/environment/climat/030723provisionaltext.pdf.

EUROSTAT (2002), Energy Database (CD-ROM), ISBN/ISSN: 92-894-3300-0, Eurostat, Brussels.

Eyckmans, J., D. van Regemorter, and V. van Steenberghe (2001), Is Kyoto fatally flawed? An Analysis with MacGEM, Working Paper Series - Faculty of Economics, University of Leuven, No. 2001-18, Leuven.

Goulder, L. H. (1995), Environmental Taxation and the Double Dividend: A Reader's Guide, International Tax and Public Finance, 2, 157-183.

Klepper, G. and S. Peterson (2002), On the Robustness of Marginal Abatement Cost Curves: The influence of World Energy Prices. Kiel Working Paper No. 1138, Institute for World Economics, Kiel.

OECD (2001), Environmentally Related Taxes in OECD Countries - Issues and Strategies, OECD Publications, Paris.

Reilly, J., R. Prinn, J. Harnisch, J. Fitzmaurice, H. Jacoby, D. Kicklighter, J. Melillo, P. Stone, A. Sokolov, and C. Wang, (1999), Multi-gas assessment of the Kyoto Protocol, Nature, $401,549-555$.

Rutherford, T. F. (1995), Extensions of GAMS for Complementarity Problems Arising in Applied Economics, Journal of Economic Dynamics and Control, 19, 1299-1324.

Rutherford, T. F. (1999), Applied General Equilibrium Modelling with MPSGE as a GAMS Subsystem: An Overview of the Modelling Framework and Syntax, Computational Economics, 14, 1-46.

Takayama, T., and G. G. Judge (1971), Spatial and Temporal Price and Allocation Models, North-Holland Publishing, Amsterdam. 


\section{Appendix A: Analytical Framework}

\section{A.1 Algebraic Model Summary}

This appendix provides an algebraic summary of the equilibrium conditions for a simple partial equilibrium model designed to investigate the economic implications of emission allocation and emissions trading in a multi-sector, multi-region framework. Emission mitigation options are captured through marginal abatement cost curves that are differentiated by sectors and regions.

Cast as a planning problem, our model corresponds to a nonlinear program that seeks a costminimizing abatement scheme subject to initial emission allocation and institutional restrictions for emissions trading between sectors and regions. The nonlinear optimization problem can be interpreted as a market equilibrium problem where prices and quantities are defined using duality theory. In this case, a system of (weak) inequalities and complementary slackness conditions replace the minimization operator yielding a so-called mixed complementarity problem (see e.g. Rutherford (1995)). ${ }^{15}$

Two classes of conditions characterize the (competitive) equilibrium for our model: zero profit conditions and market clearance conditions. The former class determines activity levels (quantities) and the latter determines prices. The economic equilibrium features complementarity between equilibrium variables and equilibrium conditions: activities will be operated as long as they break even, positive market prices imply market clearance - otherwise commodities are in excess supply and the respective prices fall to zero. ${ }^{16}$

\footnotetext{
15 The MCP formulation provides a general format for economic equilibrium problems that may not be easily studied in an optimization context. Only if the complementarity problem is "integrable" (see Takayma and Judge (1971)), the solution corresponds to the first-order conditions for a (primal or dual) programming problem. Taxes, income effects, spillovers and other externalities, however, interfere with the skew symmetry property which characterizes first order conditions for nonlinear programs.

${ }^{16}$ In this context, the term „,mixed complementarity problem“ (MCP) is straightforward: ,mixed“" indicates that the mathematical formulation is based on weak inequalities that may include a mixture of equalities and inequalities; „complementarity“ refers to complementary slackness between system variables and system conditions.
} 
In our algebraic exposition of equilibrium conditions, we use $i$ as an index for sectors and $r$ as an index for regions. ${ }^{17}$ Table A.1 explains the notations for variables and parameters.

Table A.1: $\quad$ Variables and parameters

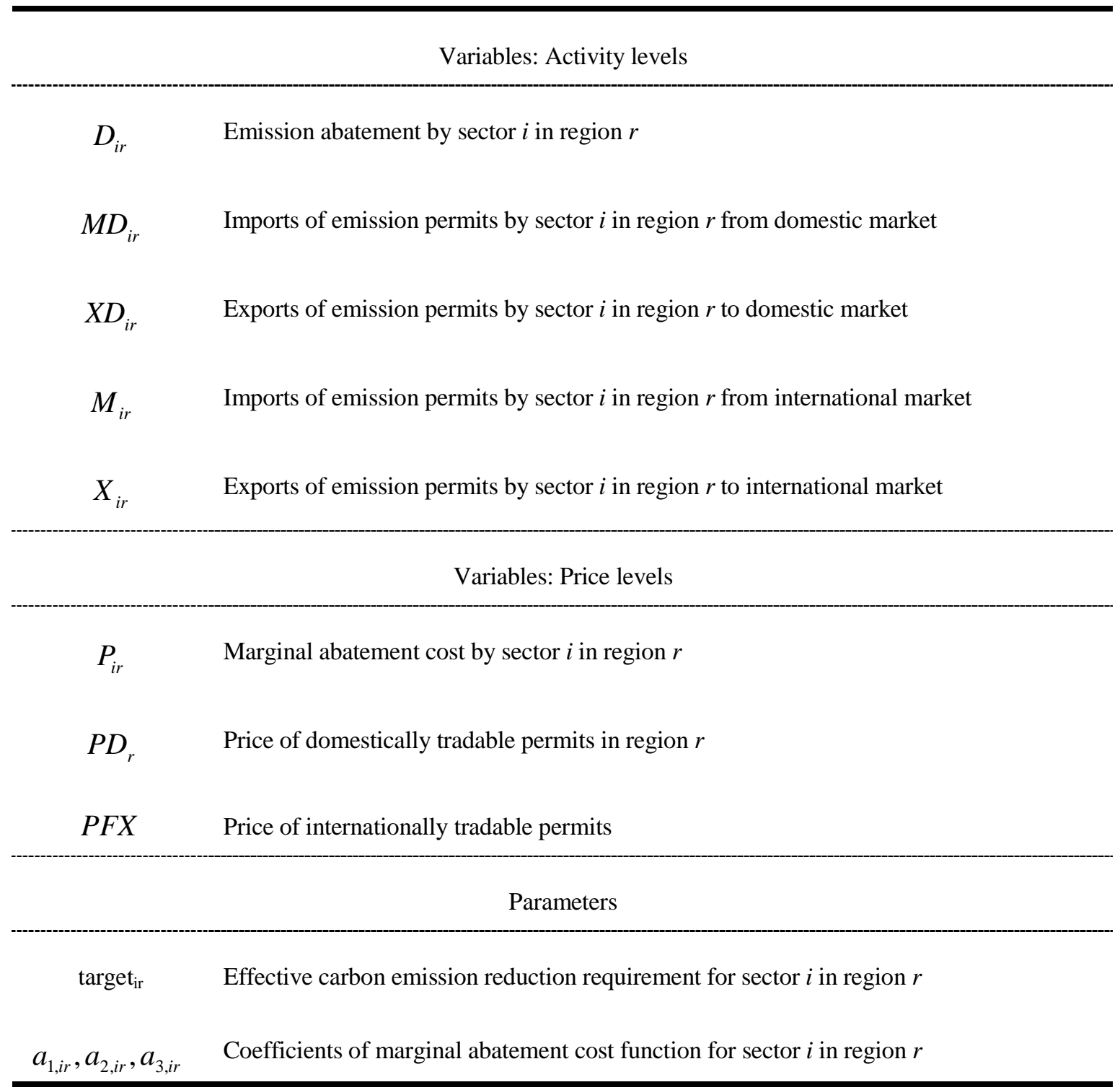

\section{Zero Profit Conditions}

1. Abatement by sector $i$ in region $r\left(\perp D_{i r}\right)$ :

$$
a_{1, i r} \cdot D_{i r}+a_{2, i r} \cdot D_{i r}^{2}+a_{3, i r} \cdot D_{i r}^{3} \geq P_{i r}
$$

2. Permit imports by sector $i$ in region $r$ from domestic market $\left(\perp M D_{i r}\right)$

\footnotetext{
${ }^{17}$ The variable associated with each equilibrium condition is added in brackets and denoted with an orthogonality symbol $(\perp)$.
} 


$$
P D_{r} \geq P_{i r}
$$

3. Permit exports by sector $i$ in region $r$ to domestic market $\left(\perp X D_{i r}\right)$

$$
P_{i r} \geq P D_{r}
$$

4. Permit imports by sector $i$ in region $r$ from international market ( $\perp M_{i r}$ )

$$
P F X \geq P_{\text {ir }}
$$

5. Permit exports by sector $i$ in region $r$ to international market $\left(\perp X_{i r}\right.$ )

$$
P_{i r} \geq P F X
$$

\section{Market Clearance Conditions}

6. Market clearance for abatement by sector $i$ in region $r\left(\perp P_{i r}\right)$ :

$$
D_{i r}+M_{i r}+M D_{i r} \geq \text { target }_{\mathrm{ir}}+X_{i r}+M_{i r}
$$

7. Market clearance for domestically tradable permits $\left(\perp P D_{i r}\right)$

$$
\sum_{i} X D_{i r} \geq \sum_{i} M D_{i r}
$$

8. Market clearance for internationally tradable permits $\left(\perp P F X_{i r}\right)$

$$
\sum_{i} X_{i r} \geq \sum_{i} M_{i r}
$$

\section{A.2 GAMS Code}

Numerically, the algebraic MCP formulation of our model is implemented in GAMS (Brooke, Kendrick and Meeraus (1987)) using PATH (Dirkse and Ferris (1995) ) as a solver. Below, we present the GAMS code to replicate the results reported in the paper. The GAMS file and the EXCEL reporting sheet can be downloaded from ftp://ftp.zew.de/pub/zew-docs/div/ nap_diy.zip. 
\$ontext

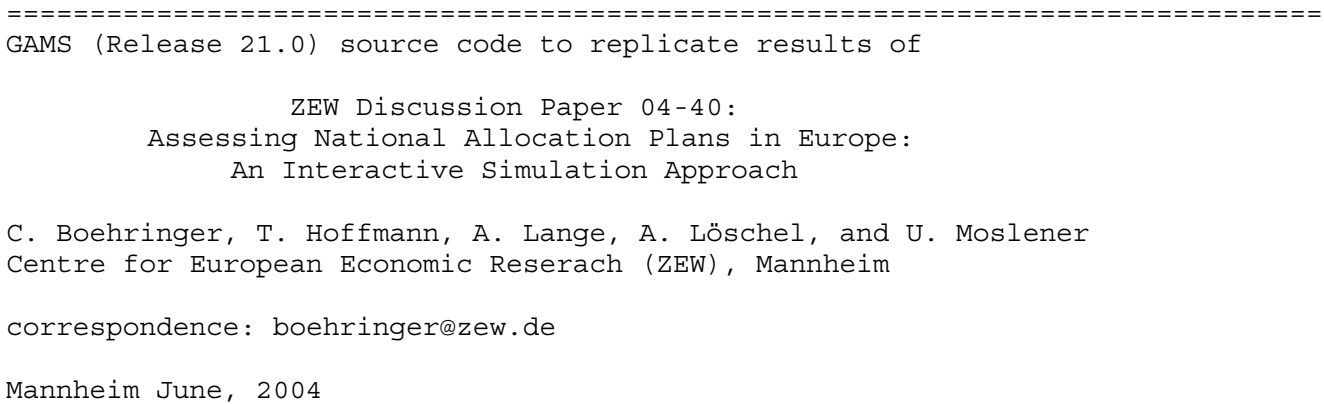

$======$
Sofftext

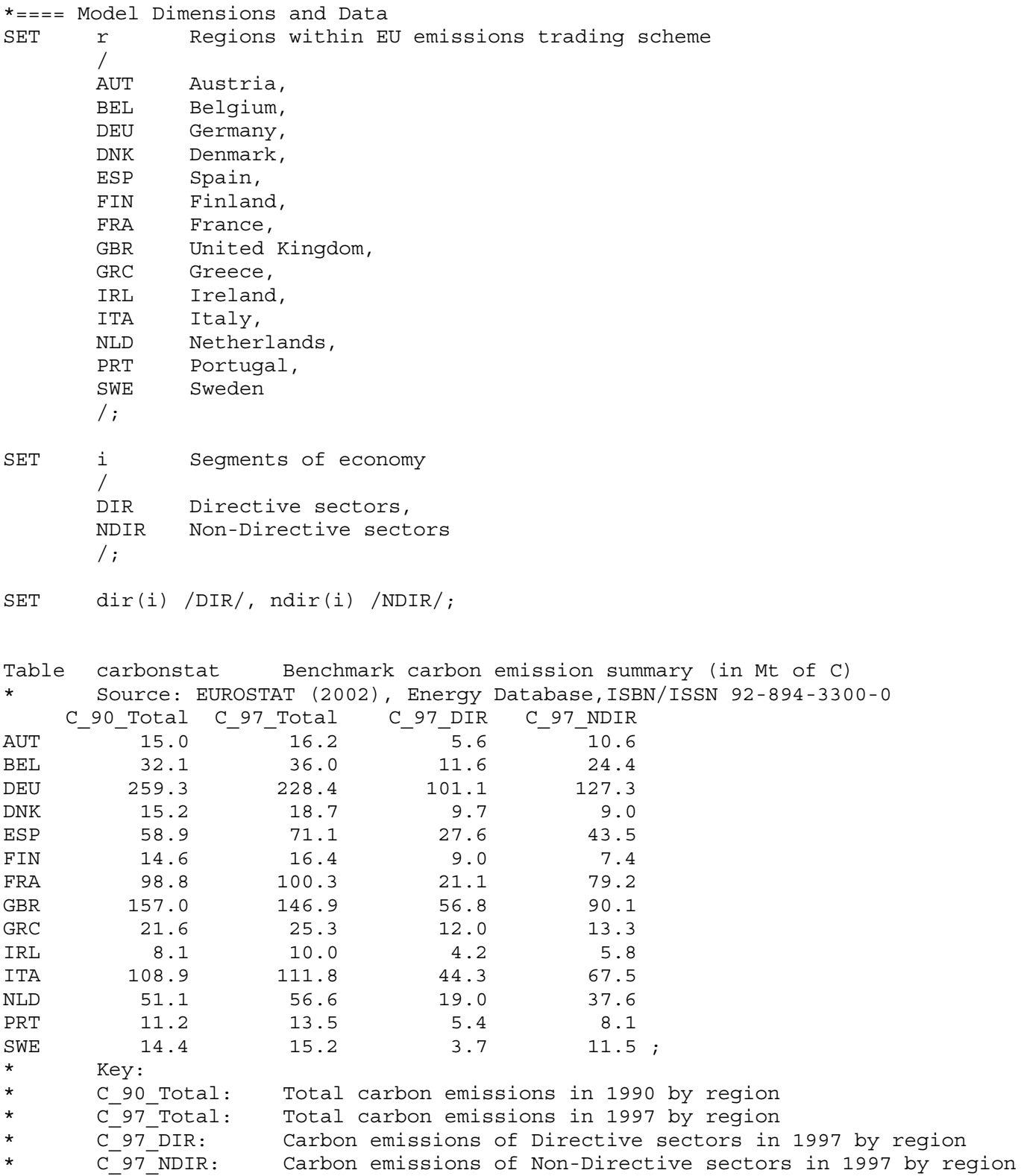




\begin{tabular}{|c|c|c|c|c|c|c|}
\hline $\begin{array}{l}\text { TABLE } \\
\star\end{array}$ & \multicolumn{2}{|c|}{ mac_coef $(r, i, *)$} & \multicolumn{4}{|c|}{$\begin{array}{l}\text { Exogenous coefficients for MAC function } \\
\text { (here: polynomial of third degree) }\end{array}$} \\
\hline * & Source: O & calculatic & s based on & uropean CGF & odel (Böhr & ger 2002: \\
\hline \multirow[t]{2}{*}{ * } & Applied E & omics, 34, & $523-533)$ & & & \\
\hline & DIR.aI & DIR.a2 & DIR.a3 & NDIR.a1 & NDIR.a2 & NDIR.a3 \\
\hline AUT & 33.89602 & 6.23977 & 9.38573 & 153.67840 & 11.28374 & 34.89848 \\
\hline BEL & 13.60163 & -0.48508 & 0.98647 & 32.68014 & 2.28401 & 0.35231 \\
\hline $\mathrm{DEU}$ & 1.60372 & 0.00318 & 0.00042 & 5.76568 & 0.08324 & 0.00095 \\
\hline DNK & 8.56613 & -1.81555 & 0.45910 & 94.96873 & 29.04864 & -0.77840 \\
\hline ESP & 6.28601 & -0.00715 & 0.07213 & 18.32066 & 0.77646 & 0.01453 \\
\hline FIN & 26.44297 & 3.40724 & 1.00766 & 104.06960 & 30.23331 & 16.55028 \\
\hline FRA & 11.26670 & 0.59175 & 0.25369 & 8.85555 & 0.23857 & 0.00387 \\
\hline GBR & 4.07568 & 0.07888 & 0.00764 & 6.96756 & 0.11765 & 0.00188 \\
\hline GRC & 19.52391 & -1.08455 & 0.44979 & 61.58611 & 2.87499 & 2.35554 \\
\hline IRL & 8.55214 & 19.52084 & 15.70231 & 169.52670 & 61.00378 & 41.42915 \\
\hline ITA & 4.41291 & 0.10278 & 0.01290 & 12.77975 & -0.40161 & 0.11182 \\
\hline NLD & 3.61171 & 1.22083 & 0.08135 & 18.21548 & 0.51576 & 0.07399 \\
\hline PRT & 29.19865 & -1.43556 & 9.85353 & 83.65847 & 28.47781 & -1.26674 \\
\hline SWE & 49.50944 & 0.32218 & 38.25903 & 104.01410 & 14.25379 & -0.06324 \\
\hline
\end{tabular}

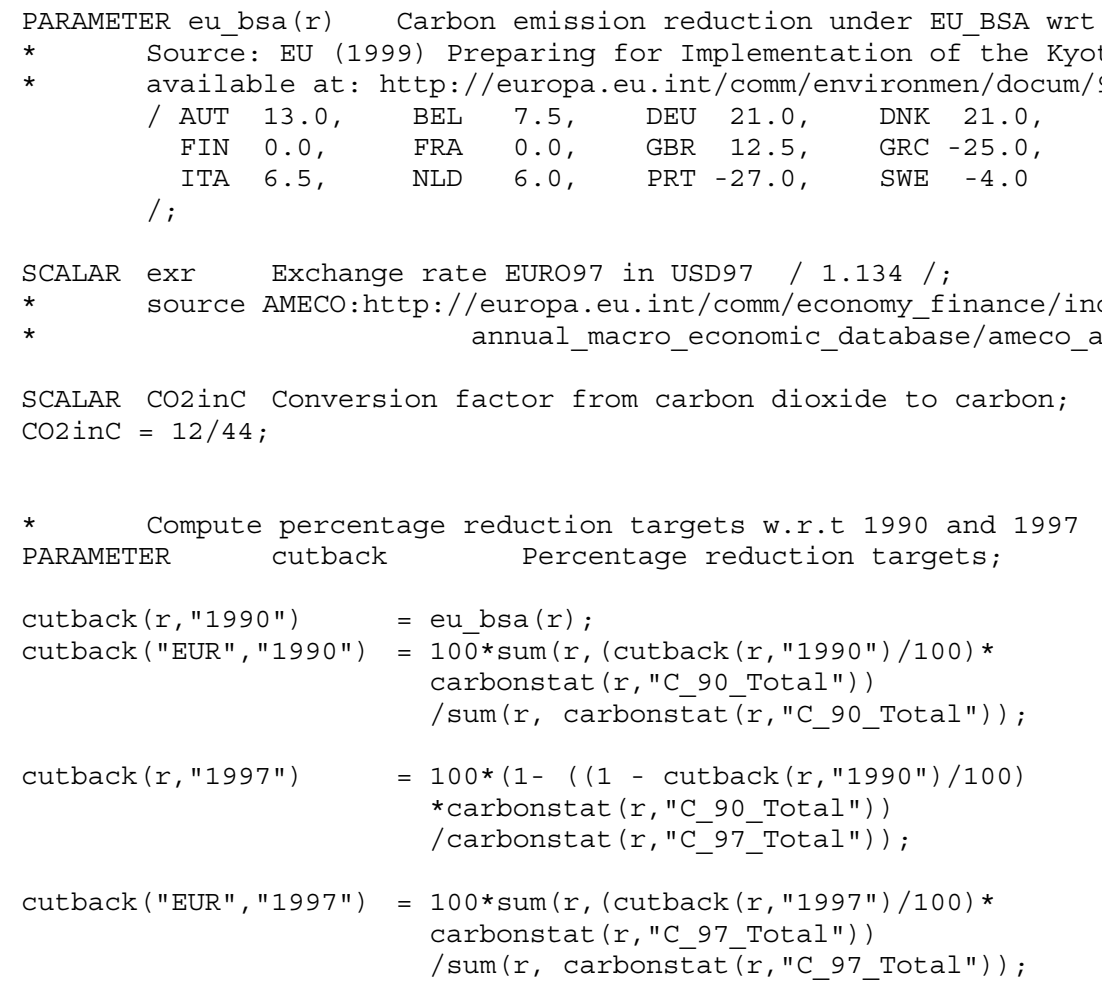

OPTION cutback:1:1:1;

DISPLAY cutback;

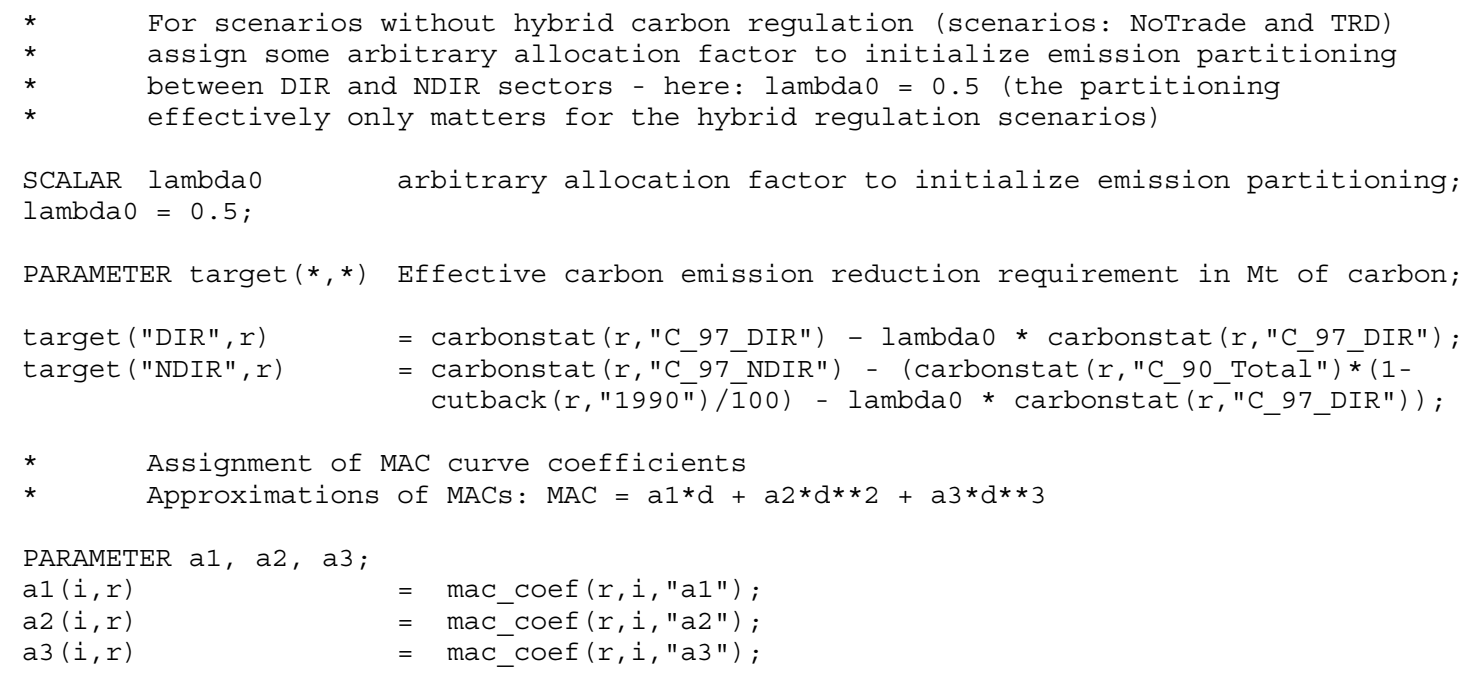


DISPLAY a1, a2, a3, target;

* Define subset of regions if some regions should be omitted from analysis SET re $(r) ; \quad r e(r)=$ YES;

*==== Model Definition (as a Mixed Complementarity Problem)

POSITIVE VARIABLES

$\mathrm{p}(i, r) \quad$ Marginal abatement cost by sector $i$ in region $r$,

pfx Internationally tradable permit price,

pd $(r) \quad$ Domestically tradable permit price in region $r$,

$d(i, r) \quad$ Abatement by sector $i$ in region $r$,

$x(i, r) \quad$ Exports of permits by sector $i$ in region $r$ to international market,

$\mathrm{m}(i, r) \quad$ Imports of permits by sector $i$ in region $r$ from international market,

$x d(i, r) \quad$ Exports of permits by sector $i$ in region $r$ to domestic market,

md $(i, r) \quad$ Imports of permits by sector $i$ in region $r$ from domestic market:

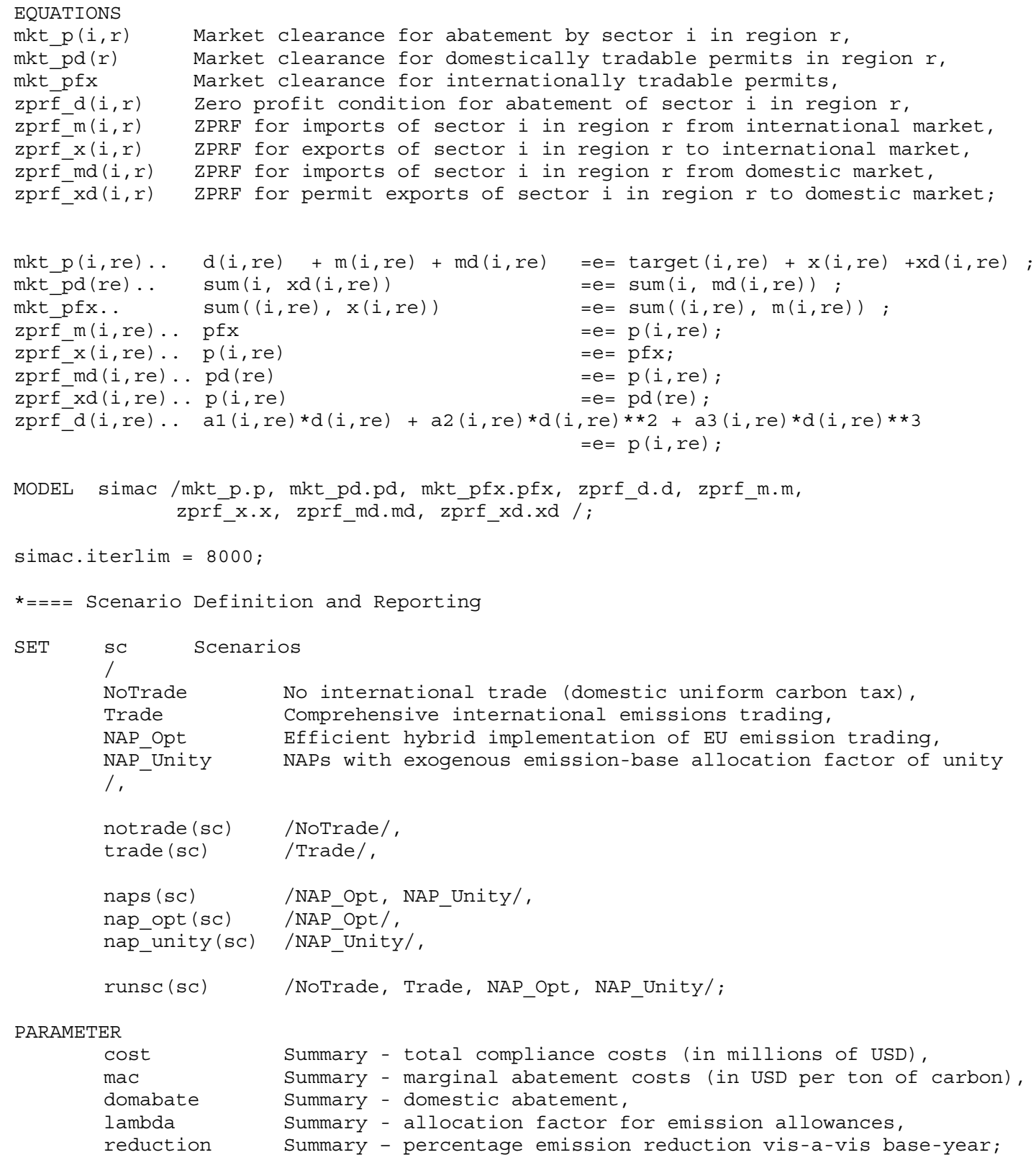

\footnotetext{
* Scenario Trade is the benchmark for defining efficient allocation factors in a * hybrid system. We therefore do an initial solve for comprehensive trading to * determine the optimal allocation factor.

$x \cdot \operatorname{UP}(i, r e) \quad=+I N F$;

$m \cdot \operatorname{UP}(i, r e) \quad=+I N F$;
} 
SOLVE simac using mcp; lambda (re, "NAP Opt")
$=($ carbonstat (re, "C 90 Total")*(1-cutback (re, "1990")/100) (carbonstat (re, "C_97_NDIR") -d.I ("NDIR", re)) ) / carbonstat (re, "C 97 DIR") ;

$\begin{array}{ll}\text { LOOP (SC\$RUNSC (SC), } & \\ \text { x.LO }(i, r e) & =; \\ \text { m.LO }(i, r e) & =0 ; \\ \text { xd.LO ("DIR", re) } & =0 ; \\ \text { md.LO ("DIR", re) } & =0 ; \\ \text { pfx.LO } & =0 ; \\ \text { x.UP }(i, r e) & =+i n f ; \\ \text { m.UP }(i, r e) & =+i n f ; \\ \text { xd.UP ("DIR", re) } & =+i n f ; \\ \text { md.UP ("DIR", re) } & =+i n f ; \\ \text { pfx.UP } & =+i n f ;\end{array}$

IF (notrade (SC)

* No international emissions trading:

$\begin{array}{ll}x \cdot F X(i, r e) & =0 \\ \operatorname{m.FX}(i, r e) & =0 \\ \operatorname{pfx} . \mathrm{FX} & =0\end{array}$

) ;

IF ( trade ( $\mathrm{sc})$,

* Comprehensive international emissions trading:

$x \cdot \operatorname{UP}(i, r e) \quad=+I N F$

$m \cdot \operatorname{UP}(i, r e) \quad=+\mathrm{INF}$

pfx.UP

)

IF (nap_opt ( $\mathrm{sc}$ )

* Efficient implementation of hybrid NAP system

target ("DIR", re) = carbonstat (re, "C 97 DIR") - lambda (re, "NAP Opt") \#

* carbonstat (re, "C_ $\overline{9} 7$ DIR") ;

target ("NDIR", re) = carbonstat (re, "C $9 \overline{7}$ NDIR") -

(carbonstat (re, "C 90 Total")*(1- cutback (re,"1990")/100)

X.FX ("NDIR", re)

- lambda (re, "NAP_Opt") *Carbonstat (re, "C_97_DIR")) ;

pfX.UP $\quad=+I N F ;$

$\mathrm{xd} . \mathrm{FX}(" \mathrm{DIR} ", \mathrm{re}) \quad=0$;

md.FX("DIR", re) = 0 ;

);

IF (nap_unity (sc)

* Implementation of hybrid NAP with emission based allocation factor of unity

* (base year: 1997)

target ("DIR", re) = carbonstat (re,"C_97_DIR") - 1* carbonstat (re, "C_97_DIR");

target ("NDIR", re) = carbonstat (re, "C 97 NDIR") - (carbonstat (re, "C 90 Total")

*(1- cutback (re, "1990")/100)

$\mathrm{x} . \mathrm{FX}(" \mathrm{NDIR} ", \mathrm{re}) \quad=0$

m.FX ("NDIR", re) $\quad=0$;

pfx.UP

$\mathrm{xd} . \mathrm{FX}(" \mathrm{DIR} ", \mathrm{re}) \quad=0$

md.FX ("DIR", re) = 0 ;

md.l $(i, r e)=0 ; x d . l(i, r e)=0 ; \operatorname{m.l}(i, r e)=0 ; x . l(i, r e)=0 ;$

d.l $(i, r e)=0 ;$ pfx.l $=0 ; p . l(i, r e)=0$

SOLVE simac using mcp;

cost (re, "DIR", sc)

$=\operatorname{eps}+\operatorname{ROUND}(\quad \operatorname{sum}(i \$ D I R(I)$

$(1 / 2) * a 1(i, r e) * d .1(i, r e) * * 2$

$+(1 / 3) * a 2(i$, re $) * d .1$ (i, re $) * * 3$

$+(1 / 4) * a 3(i, r e) * d .1(i, r e) * * 4)$

$+\operatorname{sum}(i,(\operatorname{m.l}(i, r e)-\operatorname{x.l}(i, r e)) * \operatorname{pfx} .1)), 1)$;

cost (re, "NDIR", sc)

$=\operatorname{eps}+\operatorname{ROUND}($ ( $\operatorname{sum}(i \$ \operatorname{NDIR}(i)$,

$(1 / 2) * a 1(i, r e) * d .1(i, r e) * * 2$

$+(1 / 3) * a 2(i, r e) * d .1(i, r e) * * 3$

$+(1 / 4) * a 3(i, r e) * d .1(i, r e) * * 4)), 1)$; 


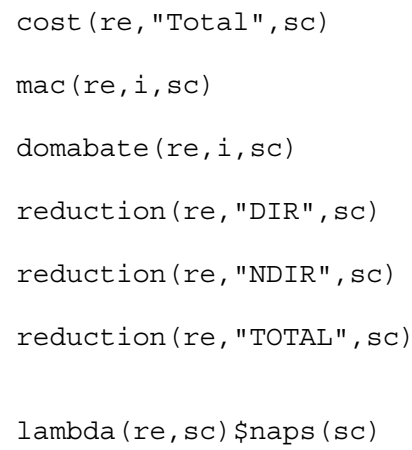

$=\operatorname{cost}(r e, " D I R ", s c)+\operatorname{cost}(r e, " N D I R ", s c)$;

$=\operatorname{eps}+\operatorname{ROUND}(\mathrm{p} .1(i, r e), 1) ;$

$=\operatorname{eps}+\operatorname{ROUND}(\mathrm{d} .1(i, r e), 2) ;$

$=\operatorname{ROUND}(100 * \mathrm{~d} .1$ ("DIR", re)/carbonstat (re, "C_97_DIR")，1);

= ROUND (100* d.1 ("NDIR", re)/carbonstat (re,"C_97_DIR"), 1) ;

$=\operatorname{ROUND}(100 *$

sum(i,d.1(i,re))/carbonstat (re, "C_97_TOTAL")，1)；

1\$(not d.I ("NDIR", re)) + [ (carbonstat (re, "C 90 Total")* (1cutback (re, "1990")/100) - (carbonstat (re, "C_97_NDIR") d.I ("NDIR", re)))

/ carbonstat (re, "C 97 DIR")]\$(d.I("NDIR", re)) ;

) ;

DISPLAY cost, mac, domabate, lambda, reduction;

* $====$ Replicate Tables of Paper

PARAMETER C 2010 Projected carbon emissions by region in 2010

* Source: Energy Policies of IEA Countries - 2001 Review (Compendium), IEA publications $\begin{array}{lllllll}\text { / AUT 17.5, } & \text { BEL 31.4, } & \text { DEU 228.5, } & \text { DNK 16.1, } & \text { ESP } 78.8, \\ \text { FIN 17.7, } & \text { FRA 126.0, } & \text { GBR 159.5, } & \text { GRC 36.5, } & \text { IRL } 12.8, \\ \text { ITA 123.0, } & \text { NLD 50.7, } & \text { PRT 16.6, } & \text { SWE } 14.5 / ; & & \end{array}$

\section{PARAMETER}

table 2 Table 2 of paper "CO2 emissions and reduction requirements",

table_4 Table 4 of paper "Marginal abatement costs and total compliance costs",

table_5 Table 5 of paper "Allocation factors and emission reduction";

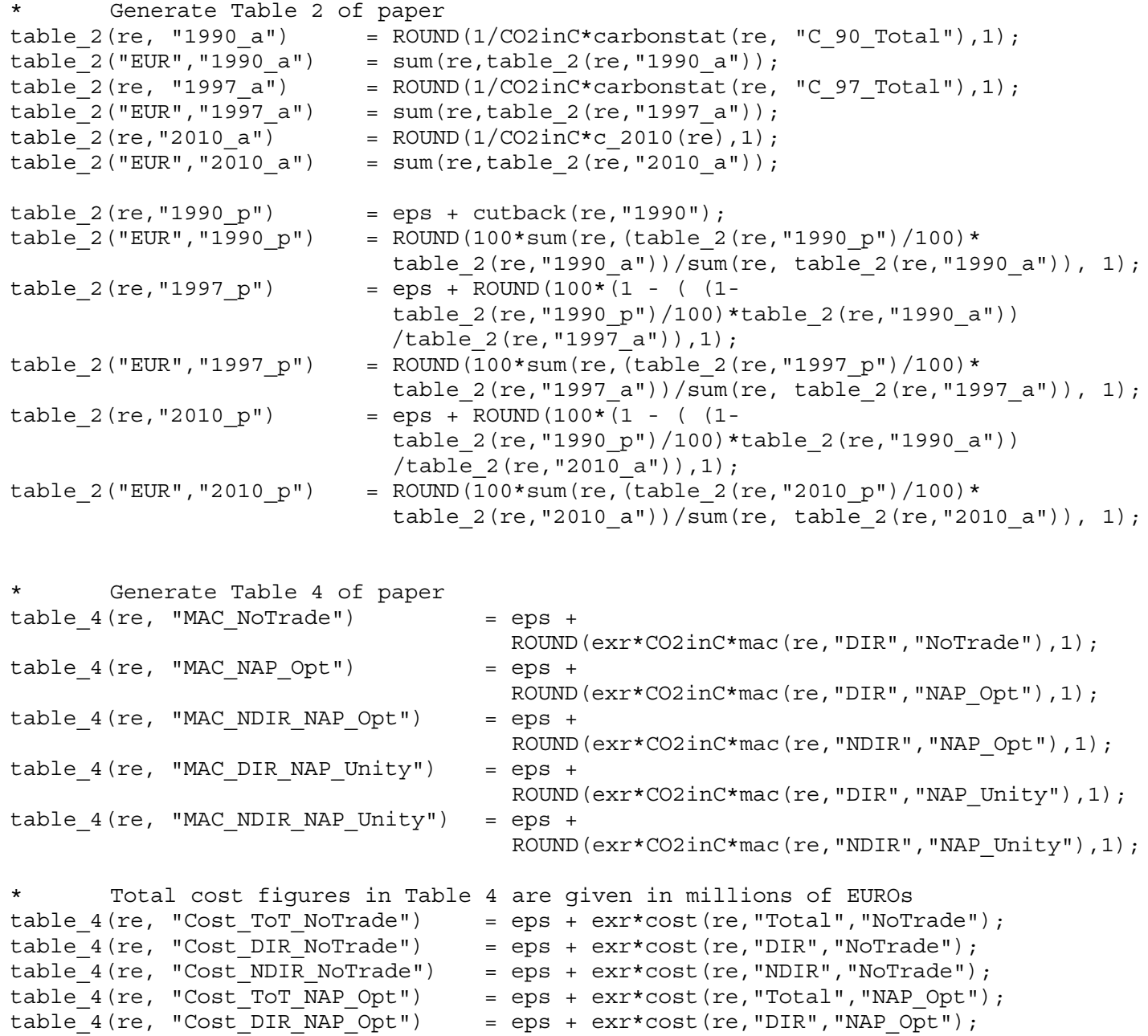




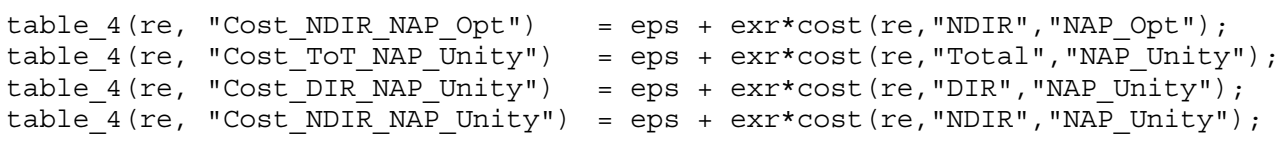

\$libinclude xlexport table_2 tables.xls table_2!table_2

slibinclude xlexport table 4 tables.xls table 4 !table 4

\$libinclude xlexport table_5 tables.xls table_5!table_5 


\section{Appendix B: User-Guide to the SIMAC-Model Interface}

In order to make our model accessible to the non-technical reader we developed a web-based interface. Under http://brw.zew.de/simac/ the user can replicate the scenarios described in Section 4 of the paper as well as specify and compute new ones. The model simulates the userdefined implementation of the EU Burden Sharing Agreement under a hybrid regulation system. It reports marginal abatement costs, total compliance costs, and emission reductions for sectors covered by the EU emissions Directive (DIR sectors) and the sectors that are not covered by the Directive (NDIR sectors). The web-based interface enables the user to

- $\quad$ specify the division of the national emissions budget between DIR and NDIR sectors,

- specify alternative historic and base-year emissions,

- specify alternative abatement cost functions at the county level for the DIR sectors and the NDIR sectors separately, and

- $\quad$ save the specified scenarios and simulation results within a personal user account.

\section{Login}

The interface is accessible through http://brw.zew.de/simac/. The user is required to log in by providing a username and a password (username and password may consist of letters and digits, special characters are not allowed).

Figure B.1: SIMAC Login screen

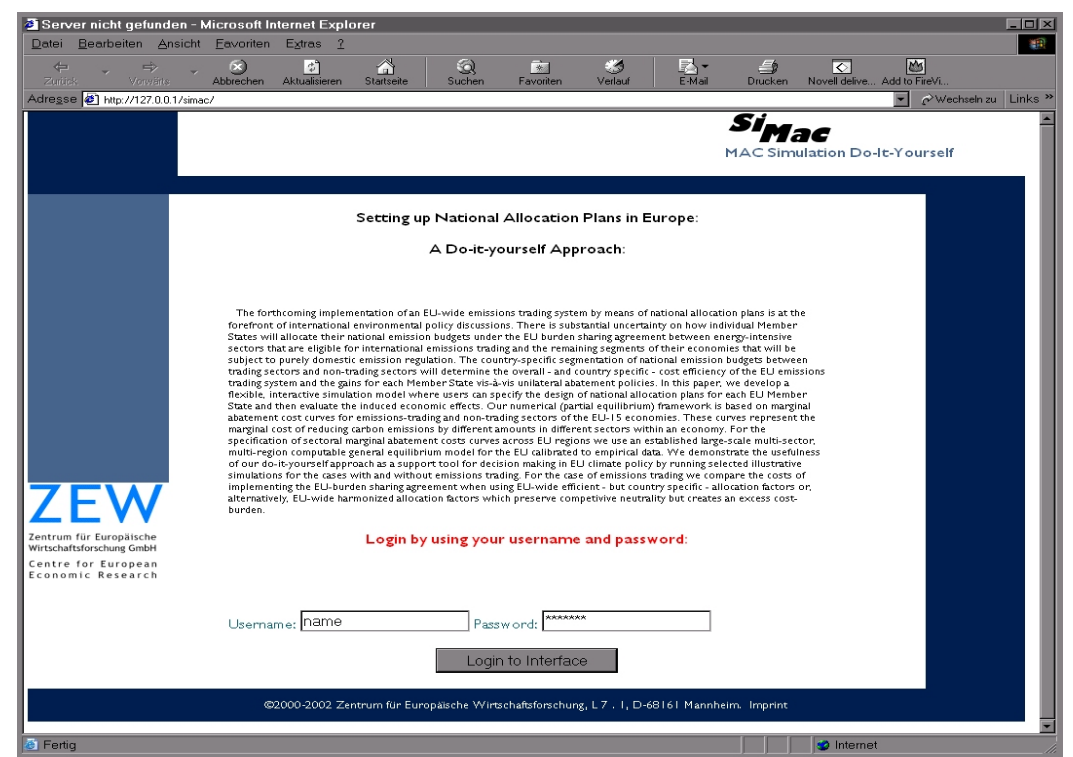


The click on the button "Login to Interface" invokes a check if the user is already known or not. In the latter case a new user account will be automatically created. Clicking the button "Proceed to Interface" then leads the user to the main input and result screen.

Figure B.2: Login confirmation

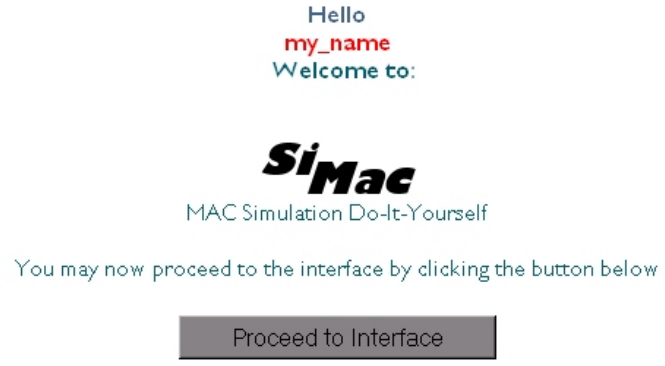

On the left hand side of the screen there is a box that lists all previously defined user scenarios. As a default - following the analysis in our paper - the interface provides (i) a scenario with full regional and sectoral "where-flexibility" $\left(N A P \_O p t\right)$ and (ii) a scenario with full regional flexibility but restricted sectoral flexibility (NAP_Unity) assuming a allocation factor of unity for the DIR sectors across all countries).

Figure B.3: SIMAC main screen

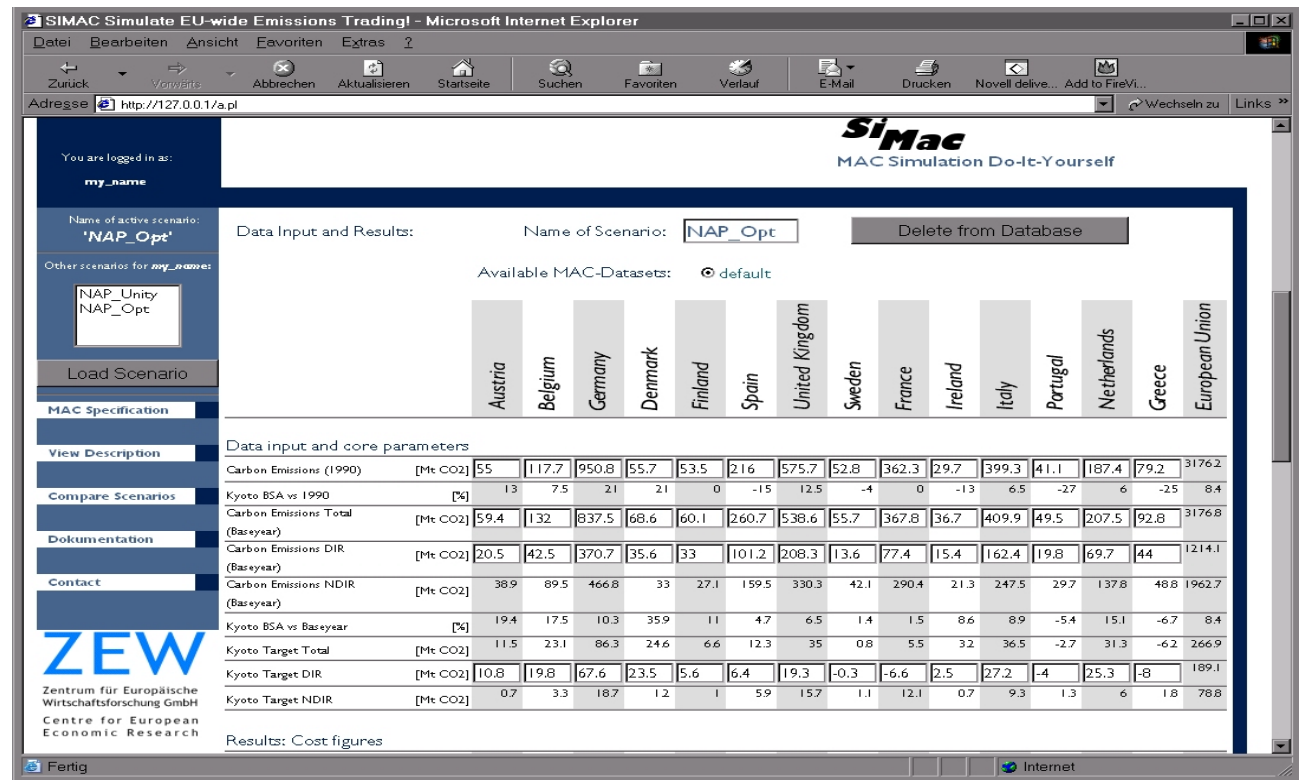




\section{Loading a scenario}

A previously defined scenario can be activated by selecting the name in the list followed by a click on the button "Load Scenario". The scenario will be loaded from the database and displayed with all associated parameters. The field "Name of Scenario" above the scenario table always shows the name of the active scenario.

Figure B.4: Loading a scenario

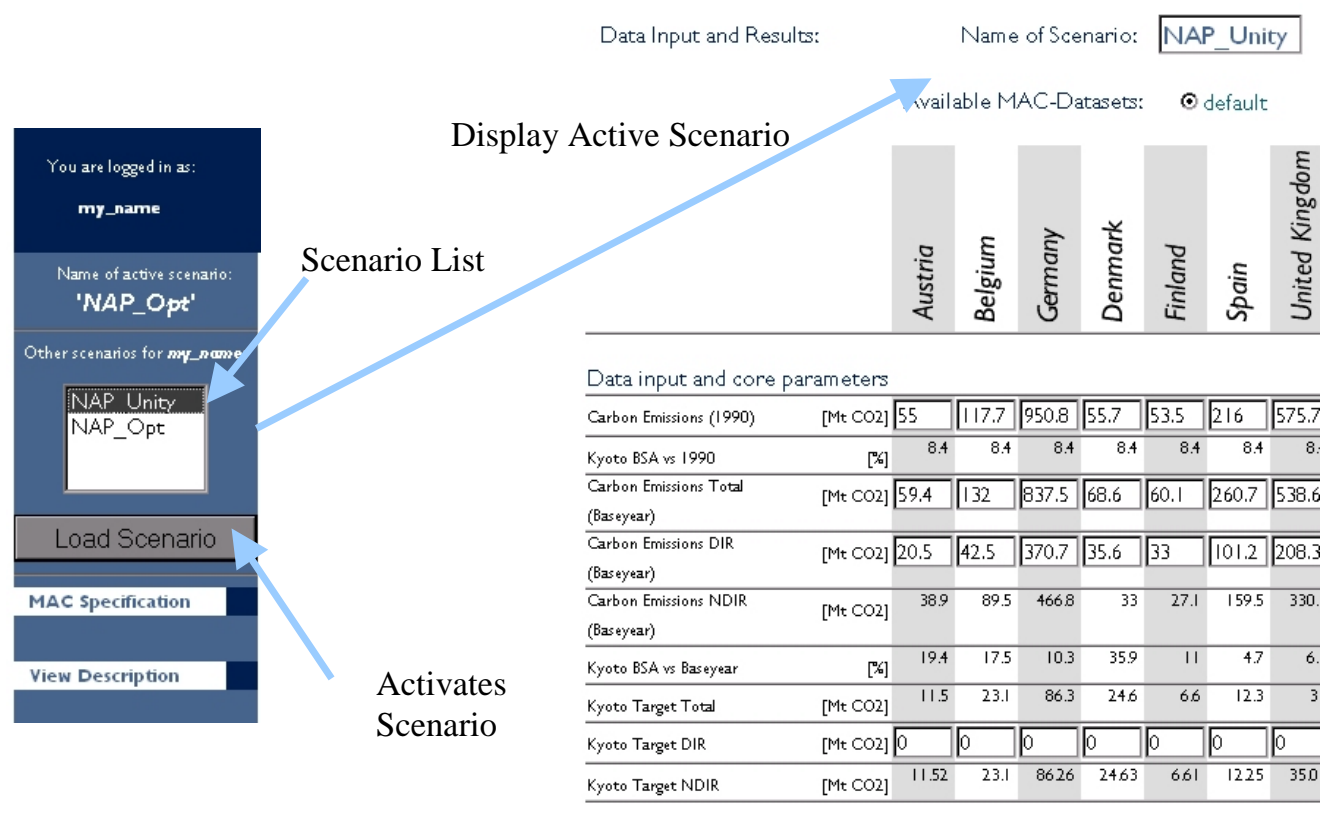

\section{Creating a new scenario}

To create a new scenario the user must provide a name for it (field "Name of Scenario" on top of the page). Subsequently, the desired input values can be specified in the framed entry fields. Four different input values can be entered at the country level:

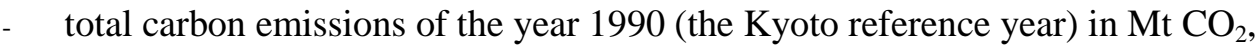

- carbon emissions of some desired base-year in $\mathrm{Mt} \mathrm{CO}_{2}$,

- carbon emissions of the DIR sectors in the base-year and

- emission reduction targets of the DIR sectors in $\mathrm{Mt} \mathrm{CO}_{2}$. 
A click on the button "Calculate and Save Scenario" starts the simulation on the server. After performing the calculations (which may take a few seconds), the scenario results are displayed on the main screen and the simulated scenario will be added to the list of available scenarios on the left hide side of the screen. For each user-defined scenario three cases will be calculated and displayed in order to provide a useful assessment:

- the results of the scenario itself ("Scenario"),

- the results assuming full regional and sectoral flexibility (“Optimal”) and

- the results assuming only domestic emission reduction ("NoTrade").

Figure B.4: Calculating a new scenario

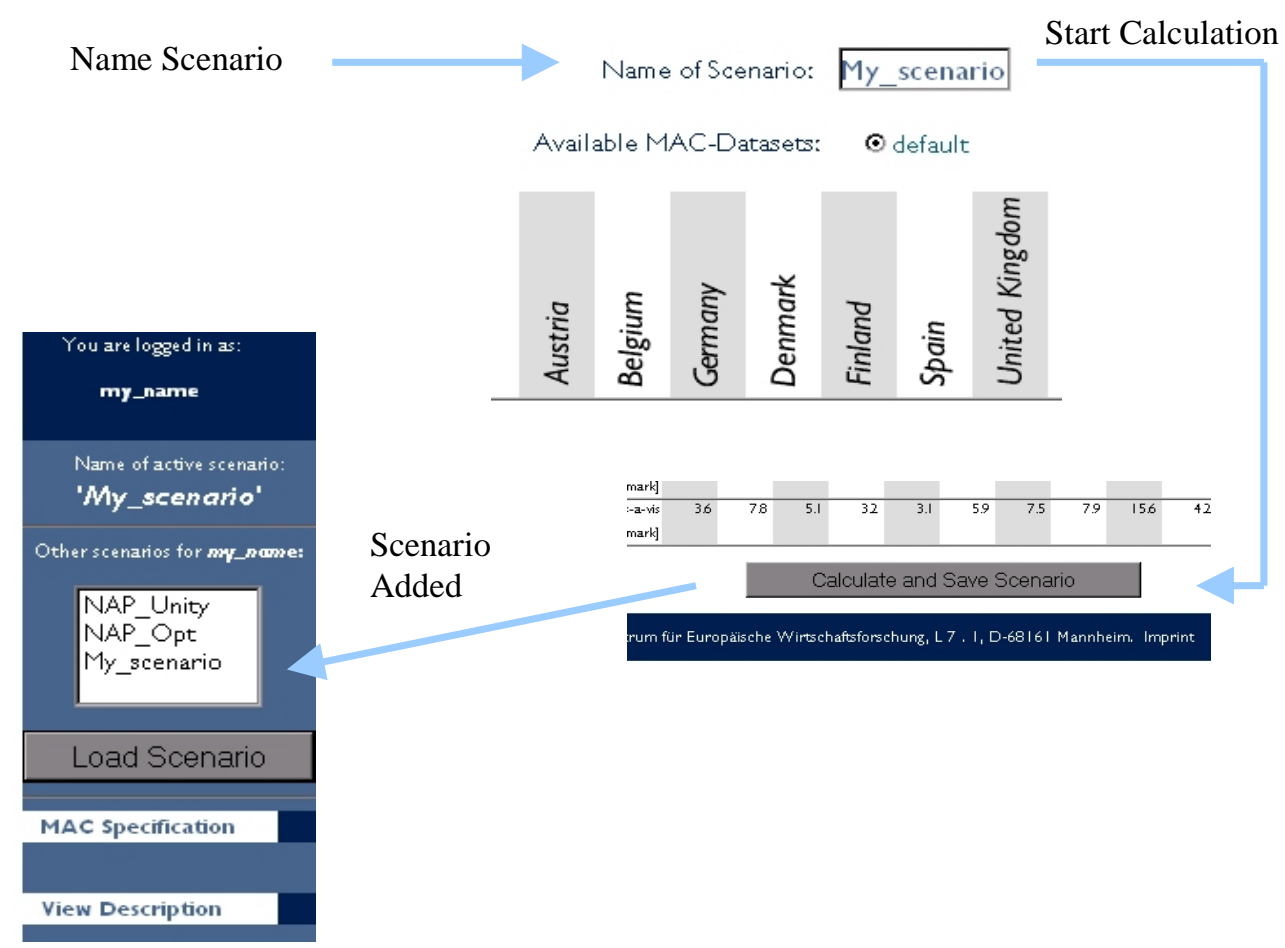

\section{Deleting a scenario}

The user may delete a scenario from the database by selecting it in the list, loading it and pressing the button "Delete from Database". Note that default scenarios cannot be deleted. 
Figure B.5: Deleting a scenario

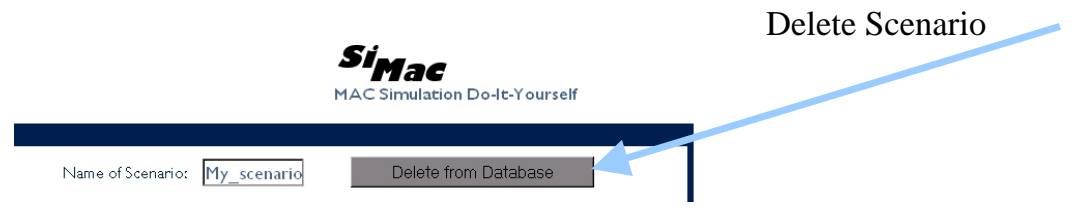

\section{Specifying coefficients for the marginal abatement cost functions}

The interface allows for the adjustment of the marginal abatement cost functions. By default all scenarios will be computed with a default set of coefficients (for the functional form of the marginal abatement cost curves and the default coefficients see Table 1 of the paper). A click on the link "MAC Specification" opens the input screen for the coefficient specification of marginal abatement cost functions at the regional level.

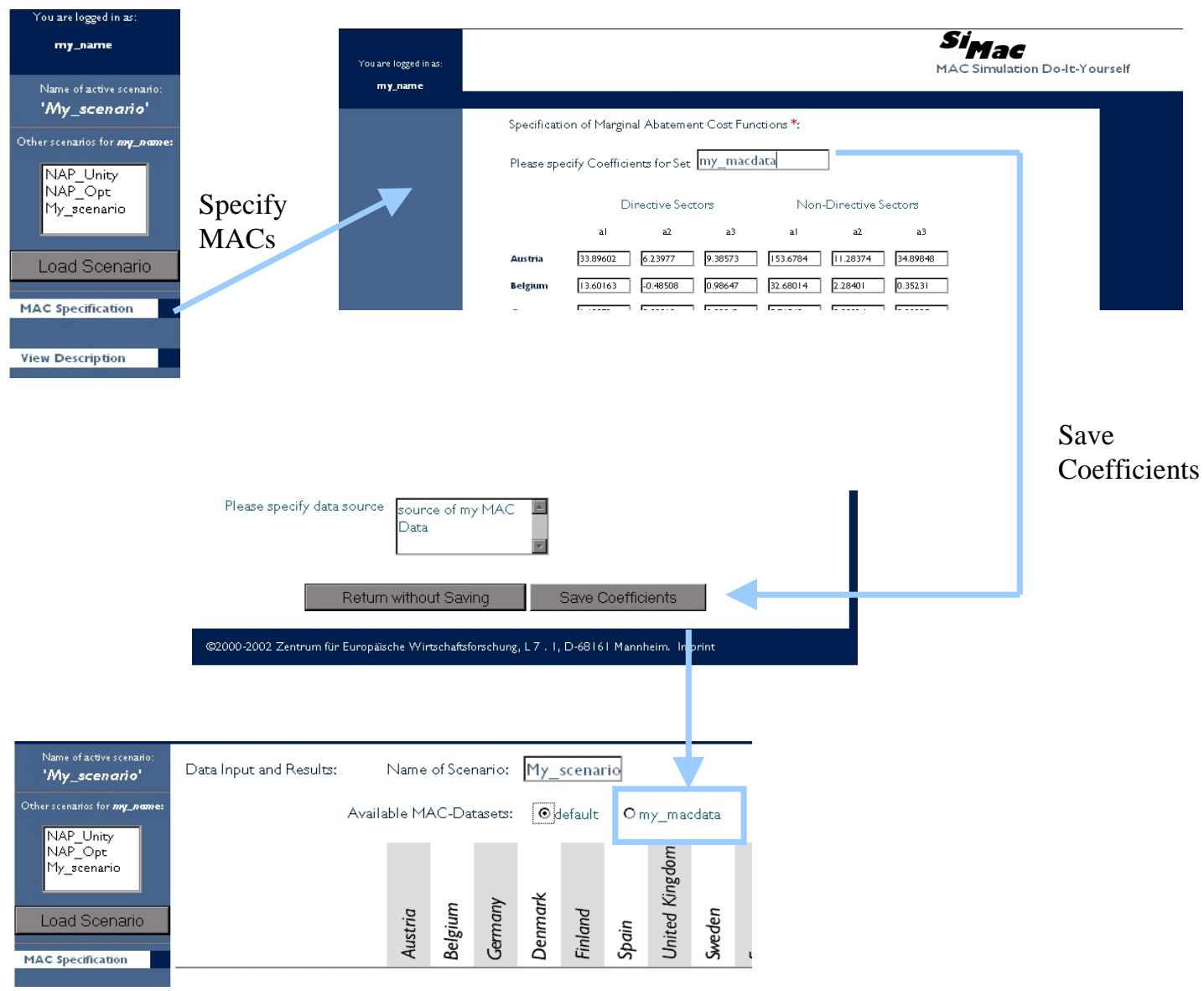

Figure B.6: Specification of marginal abatement cost functions

The interface provides alternative sets of coefficients for the marginal abatement cost functions. In order to add new coefficients, the user first must enter a new name in the field above the table with the coefficient fields. Having modified the coefficients for some or all 
countries and sectors the new set must be saved by clicking the "Save Coefficients" button. The main screen then re-appears featuring the additional dataset of coefficients as a new option for scenario specification.

\section{Technical implementation}

The core model itself is implemented in GAMS. To have it accessible through the web by different users it is linked to a web server and a RDBMS (relational database management system). The link between these applications is established by a CGI-Script (Common Gateway Interface) which is implemented in Perl (Practical Extraction and Reporting Language). The figure below illustrates the basic concept of the web-based interface.

Figure B.7: Architecture of web-based interface

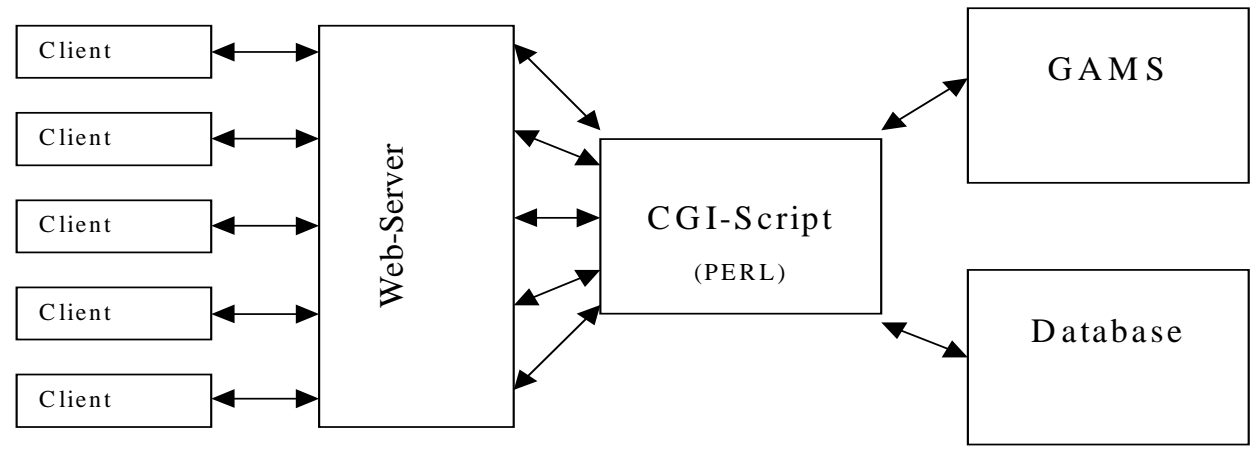

